The Best of Times and the Worst of Times: Empirical Operations and Supply Chain Management Research

\author{
Steven A. Melnyk \\ Michigan State University \\ Eli Broad School of Business \\ 632 Bogue St., Rm N327NBC \\ East Lansing, MI 48824 \\ $517-432-6410$ \\ melnyk@msu.edu \\ Newcastle Global Innovation Chair in Supply Chain Management \\ University of Newcastle \\ Newcastle, AU \\ (joint appointment) \\ Barbara B. Flynn \\ Indiana University \\ Kelley School of Business \\ 801 W. Michigan St., BS 4001 \\ Indianapolis, Indiana 46202 \\ 317-278-8586 \\ bbflynn@iu.edu \\ Fundaçao Getúlio Vargas \\ Sao Paulo, Brazil \\ (joint appointment) \\ Amrou Awaysheh \\ Indiana University \\ Kelley School of Business \\ 801 W. Michigan St., BS 4001 \\ Indianapolis, Indiana 46202 \\ 317-274-0955 \\ awaysheh@iu.edu
}

This is the author's manuscript of the article published in final edited form as:

Melnyk, S. A., Flynn, B. B., \& Awaysheh, A. (2018). The best of times and the worst of times: empirical operations and supply chain management research. International Journal of Production Research, 56(1-2), 164-192.

https://doi.org/10.1080/00207543.2017.1391423 


\title{
The Best of Times and the Worst of Times: Empirical Operations and Supply Chain Management Research
}

\begin{abstract}
We assess the current state of empirical research in operations and supply chain management (OSM), using Dickens' contrast between the best of times and the worst of times as a frame. The best of times refers to the future that empirical OSM research is now entering, with exciting opportunities available using big data and other new data sources, new empirical approaches and analytical techniques, and innovative tools for developing theory. These are well aligned with new research questions related to the digital economy, Industry 4.0, the impact of the millennial generation as consumers, social media, 3D printing, etc. However, we also explore how it is the worst of times, focusing on the challenges and problems that plague empirical OSM research. Our goal is to show how OSM researchers can learn from the worst of times, in order to be poised to take advantage of the best of times. We introduce the research diamond as a vehicle for emphasizing the importance of a balanced research perspective that treats the research problem, theory, data collection and data analysis as equally important, requiring alignment between them. By learning and addressing the issues in this period of the best of times and the worst of times, we can take advantage of the opportunities facing our field to generate research that is balanced, insightful, rigorous, relevant, impactful and interesting.
\end{abstract}


It was the best of times, it was the worst of times, it was the age of wisdom, it was the age of foolishness it was the epoch of belief, it was the epoch of incredulity, ...it was the spring of hope, it was the winter of despair... (Charles Dickens: $A$ Tale of Two Cities).

\section{INTRODUCTION}

Although written to describe Paris and London before and during the French revolution, these same words might also have been written to describe the state of empirical operations and supply chain management (OSM) research today. Like the world described by Dickens, empirical OSM research is undergoing a period of profound change that significantly affects both theory and practice. Empirical research methodologies have become widely accepted as valid for investigating some types of research problems, and OSM researchers are well trained in them and poised to take up this challenge. In this sense, it is the best of times.

Yet, some have questioned whether empirical approaches will continue to play an important role in OSM research in the future. There is an abundance of empirical OSM research that exhibits issues relating to the balance between the research problem, theoretical lens, data collection strategy and data analysis strategy that can cause it to be viewed as unimportant, irrelevant or untrustworthy. In this sense, it is the worst of times. While the future promises OSM empirical researchers exciting opportunities to do impactful research of interest to researchers and practitioners, potentially an age of wisdom, it is also a time of significant issues. These issues are not insurmountable; however, thus we present solutions from a compilation of sources, providing a spring of hope for empirical OSM researchers.

OSM is undergoing significant changes, due to a number of developments that are rapidly converging, including advances in technology related to the advent, acceptance and spread of Internet of Things (IoT) and smart devices, increased importance of social media, changes in robotics that have simplified their use, deployment and costs, as well as increasing their range of 
applicability, improvements in 3D printing that have simultaneously reduced costs and enhanced its range of applicability and many other important areas. In addition, there has been an explosion of Big Data (BD), along with associated analytics. Finally, there are changes in the marketplace itself. Millennials are replacing baby boomers as the major market segment and drivers of demand. They bring with them new demands that have OSM implications, including expecting a personalized customer experience, caring about the values of the companies they buy from, expecting their technology to work, valuing collaboration and co-creation, and desiring convenience and speed, without cost (Solomon, 2014). There is confusion and concern in both the practitioner and researcher worlds regarding what the future of OSM will look like and how it will operate. This creates demand from practitioners for rigorous, relevant research, which academics are well positioned to deliver, provided that that it is appropriately structured, driven by interesting research questions, grounded in relevant theory and properly executed.

Consequently, the time is right for the OSM profession to take stock of its empirical research in this highly dynamic environment, with a goal of reengineering our skills in light of the changes taking place. Thus, our research question is what can OSM researchers do to improve their empirical research, in order to ensure that it is interesting, relevant and trustworthy in the present and future? We provide recommendations to prevent this from becoming an age of foolishness or a winter of despair. We build our observations on our combined experience of over 70 years as researchers, reviewers, associate editors and editors, using a diamond-shaped model as the framework, in order to emphasize the importance of a balanced perspective. In the following sections, we focus on the four points of the research diamond, describing both issues (winter of despair) and opportunities (spring of hope) associated with each.

\section{OSM Empirical Research Today}

\section{The Best of Times}


A review of any recent issue of $I J P R$ or several other journals reveals that it is the best of times for empirical OSM research, which has come a long way since its early days (Adam \& Swamidass, 1989; Flynn, et al., 1990). Survey research is commonly used to address interesting and important research problems, and it is well accepted by reviewers and readers. In addition, we are seeing more high quality non-survey empirical OSM research, including case research (Yeung, et al., 2007; Durugbo, 2013; Campbel \& Sankarani, 2005), experiments (Su, et al., 2017) event studies (Ni, et al., 2016) and other approaches that employ archival data (Jin, et al., 2016; Chong, et al., 2017; Li \& Wang, 2017; Chien, et al., 2017; van der Spoel, et al., 2017). Empirical OSM research today builds upon several well-understood theoretical lenses. Researchers are highly skilled in the design and execution of data collection strategies, and the sophistication and rigor of analysis continues to broaden and improve. However, it is important to remember that analysis is only one part of a balanced research process. While data analysis is important, it is not sufficient to compensate for an uninteresting research question, a weak theoretical lens or badly conceived data collection. The best research articles achieve a balance between these four elements, described below.

\section{The Research Diamond}

The research diamond (Figure 1), brings together the four critical elements of a balanced research paper. Although there is nothing new about any of them, we argue that many empirical OSM articles suffer from imbalance, due to researchers' preferences for theory development vs. validation or for structured data collection vs. open-ended exploration of emergent findings. The best empirical articles push beyond researchers' comfort zones to achieve a balanced treatment.

The research diamond can be envisioned as a flat, thin diamond-shaped rock that is somewhat precariously balanced on a stalagmite. The four corners of the diamond correspond to 
the four critical elements of a research paper. As long as it is uniformly thin and remains centered on the stalagmite, the rock will balance. However, if one of the points is thicker than the others or the rock shifts off center, it will tip and perhaps fall. Thus, the research process should achieve balance between the research problem, theoretical lens, data collection and data analysis, which constitute an interrelated system; changes in any element affect all of the other elements. Like a gyroscope that is self-centering, research that leans too heavily towards one of the elements can quickly careen out of control. This balancing act is at the heart of an effective research process, whether it uses a theory validation or a theory development approach; the most compelling research papers tightly integrate all of these elements.

\section{Insert Figure 1 About Here}

\section{The Research Problem}

The research problem is the issue or question addressed. An unbalanced research paper that focuses heavily in data analysis isn't sufficient to produce a high quality research paper. It may suffer from having “excellent tools for gaining answers, but a serious shortage of interesting questions” (Levitt \& Dubner, 2005). Thus, having an interesting research problem is critical in developing a research project:

...those who carefully and exhaustively verify trivial theories are soon forgotten; whereas those who cursorily and expediently verify interesting theories are long remembered (Davis, 1971).

\section{$\underline{\text { Issues }}$}

Buried Research Problem. A research problem that is muddled or obscure fails to guide the other three points of the research diamond. Examples include framing the research problem as simply a restatement of the hypotheses or failing to explicitly state what the research problem is. A reader who has to dig through a paper to find the research problem is like the little boy who 
found a pile of manure under the Christmas tree and happily started digging through it, shouting, “there’s got to be a pony in here somewhere!” Pony papers are not uncommon in OSM research; the research problem should be clearly stated in the first few paragraphs, rather than buried in rhetoric, in order to position the paper and guide decisions related to the other three points of the research diamond.

Uninteresting Research Problem. Simply stating a research problem isn't sufficient, if it the problem is uninteresting. Davis (1971) described uninteresting research questions, summarized in the first three rows of Table 1. Although developed in the context of sociology, the same issues are reminiscent of some OSM papers. For example, many "gap" studies fall in the "irrelevant" category; just because something hasn't been studied previously doesn't mean that it is interesting or important. Rather, OSM researchers are challenged to develop research problems characterized by the description in the fourth row of Table 1.

\section{Insert Table 1 About Here}

Conceptual Oversimplification. Oversimplified constructs and relationships can mask what the real research problem is. For example, a substantial amount of OSM empirical research conceives of a supply chain as consisting of simply a customer and a supplier or perhaps a supply chain triad (Choi \& Wu, 2009). While researchers readily acknowledge that real supply chains are more like networks (Basale \& Belamy, 2014; Benzudenhout, et al., 2012; Choi, et al., 2001), there is a tendency to focus on small fragments of supply chains. This may be justified as learning about fragments to generalize to a broader network (Benton \& Maloni, 2005), but it many cases, this conceptual oversimplification is simply for the researchers' convenience.

Research problems may also be limited by researchers' methodological limitations; if survey methods are their only skill, the supply network is assumed away so that they will be able 
to easily apply a survey to collect data. The data collection strategy should be aligned with the research question. In the case of a supply network, a deep dive into the rich details of a few supply networks using an inductive approach would be more informative than a survey.

Overly Pragmatic Problems. Many interesting research problems have their roots in current events; for example, product recalls by Mattel, Toyota and others led to interesting research problems that have guided a number of papers (e,g., Roth, et al., 2008; Hora, et al., 2011; Ni, et al., 2016). The issue with such papers, however, is the temptation to focus too heavily on the actual event, rather than placing it in the larger context of theory. This runs the risk of a paper that reads like a consulting report, rather than a research article. This can be a particular problem for action research and engaged research (Touboulic \& Walker, 2016), where the researcher becomes deeply embedded in the context of a firm. Grounding practical research problems in theory helps guide the research toward generalizable conclusions that are both practical and make an academic contribution. Thus, while research problems grounded in the real world are interesting and important, maintaining balance between the four points of the research diamond is critical to developing them into strong research.

Time Myopia. Time myopia is illustrated by cross-sectional research questions, which are typical of survey research. While acknowledgement of the need for longitudinal research questions is often part of a survey study's list of limitations, there may be a reluctance to actually tackle such problems. Longitudinal analysis faces the challenge of transitions between states, making standard data analysis approaches inappropriate. It is tempting to allow analytical shortcomings of survey methodology to dictate research questions, leading to the study of less interesting problems. Development of longitudinal case studies may be more tenable and better aligned with this type of research question than a survey. 
Space Myopia. Space myopia is related to locally focused research problems. Although OSM research is not as exclusively U.S.-focused as it was in the past, it remains mostly local; research conducted in a single country, such as China, is only generalizable to that country. Global research problems that transcend national boundaries call for comparisons between regions. There are many methodological challenges inherent in survey and case study data collection strategies that cross national boundaries (Tsui, 2006; Farh, et al., 2006), thus, as empirical OSM research moves towards truly global research problems, there will be a need to apply innovative data collection and analytical approaches.

\section{Opportunities}

Although these issues may conjure a winter of despair, we view them as opportunities to improve empirical OSM research. Thus, we pose opportunities that represent the spring of hope, helping empirical OSM research to be more significant and relevant.

Interesting Research Questions. An interesting research question (see the last row of Table 1) captures readers' attention.

The first criterion by which people judge anything they encounter, even before deciding whether it is true or false, is whether it is interesting or 'boring' (Davis, 1999, p. 245).

An interesting research question is counterintuitive, without being absurd, challenges established

theory (Bartunek, et al., 2006), and causes readers to want to read farther, by proposing something intriguing (Davis, 1971). Barley’s (2000) rock and roll metaphor (Table 2) nicely describes characteristics of interesting research questions.

\section{Insert Table 2 About Here}

Parsimony. The research problem should provide a simple, clean causal model with a strong theoretical rationale for the why underlying each link. For example, Hora and Klassen 
(2013) used only two constructs in their vignette-based experiment on knowledge acquisition during large scale, low frequency losses. This allowed them to develop a rich, detailed rationale for each hypothesis, leading to clear, concise and memorable conclusions. In contrast, OSM models often contain 10-15 constructs with 20 or so links between them, causing readers to have difficulty recalling the most important findings or even what the focal construct was.

Framing of Research Questions. A research question should have a single focal construct, which is its most memorable and interesting element (Whetton, 2009), illustrated in the first two rows of Table 3. In both examples, psychological trust is the focal construct; it is the independent variable in the first example and the dependent variable in the second. Thinking about what the focal construct is can be helpful in developing a logical and concise research question, as well as framing the theory to support it.

Insert Table 3 About Here

Contribution to Knowledge. A good research problem makes a contribution to knowledge. Huff (2009) provides a useful list of ways that research can make a contribution to knowledge, in the order of increasing diversity and doubt.

- Speculation: A curious or provocative idea or phenomenon that cannot be explained by current theory.

- Assertion: A new subject explains things (or is explained by things) that researchers should know more about.

- Clarification: Expansion of knowledge about an interesting construct by providing details about its composition or causal connections.

- Reiteration: Reinforcement that improves understanding of an interesting construct.

- Adjustment: Misunderstood or overlooked phenomena indicate that a construct has different components or causal relationships than previously believed.

- Negation: A new construct is more important or significant than a standard construct.

- Synthesis: A broader explanatory framework resolves apparent contradictions between two interesting constructs and shows how both are important.

- Redirection: A different subject is more interesting and more significant than a standard subject.

- Rebuttal: Argues or provides evidence that reestablishes that a construct is interesting and significant, although some scholars have had doubts about its importance and significance. 
Metaphors. Just as Barley's (2000) rock and roll metaphor helps define the nuances of the "interesting" construct, metaphors can be used to help a wide range of readers understand a challenging research construct (Foropon \& McLachlin, 2012). An easily visualized metaphor, like scouts hiking on a trail (Goldratt, 1992), develops understanding of difficult-to-comprehend constructs like the interaction between dependent events and statistical fluctuations. For example, Wu, et al. (2010) used a kitchen as a metaphor for subtle distinctions between operations practices, capabilities and resources. We employ a number of metaphors in this paper, including a hammer, a pony, bread dough, rock and roll, a large flat rock and a gyroscope. Examples of OSM metaphors include a sandcone (Ferdows \& DeMeyer, 1991), a funnel (Clark \& Wheelwright, 1993), boiling frogs (Cattani, et al., 2006), a canary cage (Clark \& Wheelwright, 1993) and rocks in a river.

Paradoxes. A paradox presents two contrary perspectives; taken separately, each is incontestable (Poole \& Van de Ven, 1989). Davis (1971) provided a set of generic paradoxes, summarized in Table 4. A paradox can be resolved through a shift in perspective or by posing the problem differently; thus, a paradox can be useful in developing interesting research questions. Options for dealing with a paradox include:

- Live with it

- Use temporal separation to explain it (e.g., firms at different stages of development will respond differently)

- Use managerial separation to explain it (e.g., what people at the operational level think about is different from what people at higher levels think about)

- Revise the theory to accommodate the paradox (Poole \& Van de Ven, 1989)

For example, Powell's (1995) research built on the function paradox: TQM resulted in high performance for some firms, but not others. Westphal, et al. (1997) addressed this using temporal separation, proposing that early TQM adopters were motivated by economic factors, while later adopters were motivated by customer pressure, resulting in customized vs. standardized TQM 
implementation. However, in revisiting this paradox, Benner and Veloso (2008) argued that both early and late adopters were motivated by economic factors, and Kennedy and Fiss (2009) dismissed Westphal, et al.'s (1997) two-sample approach, noting that there were equivocal outcomes related to the economic benefits of innovation adoption. In other words, both early and lagged beneficiaries exist. Thus, a paradox can lead to a research problem that inspires a stream of subsequent research.

\section{Insert Table 4 About Here}

\section{Theoretical Lens}

Thoughtful application of theory guides addressing the research problem in a manner that allows knowledge to be systematically accumulated (Amundson, 1998; Van de Ven, 1989), helping researchers generate coherent explanations, rather than data dredging (Whetton, 1989; Hambrick, 2007; Weick, 1989, 1995). As noted by Van de Ven (1989), nothing is as practical as good theory. Theory provides a way to "make sense of what would otherwise be inscrutable or unmeaning empirical findings (Gaile, et al, 2009, p. 286).” It is what makes a field like OSM a science, rather than a set of practices or an art, providing a roadmap for investigating the research problem, elucidating relevant constructs and expected relationships between them, and avoiding extraneous constructs and relationships.

Theory is independent of the data collection approach; whether a survey, case research, direct observation, action research or an experiment is used, it should be guided by theory or used as a means to develop theory. Theory validation, the approach used in OSM survey and experimental research, applies existing theory, through replication or to a novel context; it is a deductive approach. In contrast, theory development is inductive, focusing on developing unique theory that proposes new constructs and relationships or makes very major modifications to 
existing theory, often through case studies or action research. In the following sections, we describe issues with both OSM theory validation and theory development research, as well as proposing opportunities for improving each.

\section{Theory Validation}

Theory validation research builds upon deductive reasoning, which draws upon a positivist worldview (Huff, 2009). It assumes that it is possible to accept or reject claims and that observations of phenomena do not vary significantly between observers. Theory is validated by comparison and selection among different theories, typically analyzing data collected through surveys, experiments or some types of archival data. A theory validation approach applies the research diamond by beginning with formation of abstract generalizations to develop a research problem that is used to make a theoretical statement that one class of phenomena will be connected in some way to another class (Huff, 2009). Logical deduction and operationalization of the constructs form the base for implied empirical statements, which are tested by collecting observations to see whether they hold or not.

\section{Theory Validation Issues}

Insufficient Understanding of What Theory is. Although it may seem self-evident, the distinction between a literature review and a theoretical lens is not always clear, driving some OSM empirical researchers to the winter of despair. A literature review positions research in the extant literature and, as such, is a necessary part of a good research paper. However, it doesn't provide a roadmap for addressing the research problem, specify key constructs and relationships between them or describe how the research advances scientific knowledge. Much what OSM authors describe as theory is actually literature review; effective use of an appropriate theoretical lens is a hallmark of the best research papers. 
Wrong Theory. Because OSM doesn’t have a large body of unique theory, researchers borrow established theory from fields with a richer theoretical base. Commonly cited theories in empirical OSM research that have their roots in other fields include the resource based view (Barney, et al., 2001), transaction cost economics theory (Williamson, 1975, 1985), agency theory (Jensen \& Meckling, 1976, 1980), institutional theory (DiMaggio \& Powell, 1983), social network theory (Granovetter, 1973), complex adaptive systems theory (Pathak, et al., 2007; Bezudenhout, et al., 2012) and behavioral economics (Tversky \& Kahneman, 1974). However, there is a tendency to select theories (the resource based view is a particular favorite), without considering their alignment with the research problem. While some OSM research papers apply RBV very effectively, many more do not; it is not a one-size-fits-all lens for all research problems.

Forced Theory. Theory, while usually referred to by OSM empirical researchers, it isn't always employed to guide their research. When a theoretical lens is added post hoc, after empirical data has been collected and analyzed, it appears forced (Gaile, et al., 2009). This primarily descriptive approach simply reiterates what a theory states, but fails to capitalize on its power to ground a research problem in a systematic field, then use it to guide data collection and analysis. Using a theoretical lens to guide research is challenging. It is like kneading bread dough; it must be thoroughly worked in order to yield insights, along with some resting periods for reflection, allowing insights to "rise." However, with the same amount of kneading, pie dough would become tough and break apart, thus, good bakers avoid overworking pie dough. OSM researchers often treat theory as though it were pie dough, avoiding overworking it. However, it is only through thoroughly working theory, along with reflecting upon it, that important insights result.

Overreliance on Economics-Based Theories. OSM validation research applies several economics-based theories, such as RBV, transaction cost economics theory and agency theory, 
which assume that decision making is driven by an optimality goal and that behavior occurs in a state of equilibrium and rational determination (Bromiley, 2005). However, optimization may be impossible because of missing information or the complexity of real world research problems (Simon, 1979). Thus, many economics-based theories have not performed well in an OSM context (Bromiley, 2005), suggesting the need for theory development, rather than theory validation, for some research questions and the need for applying other theory bases.

Misapplied Theory. Sometimes an appropriate theory is applied, but it is not applied properly, resulting from a tendency to repeat what was learned from other authors' descriptions of the theory, rather than reading the original theoretical exposition. This is akin to reading the Cliff Notes version of a classic piece of literature, rather than reading the actual book; while popular among high school students trying to outsmart their English teachers, it isn't a good approach to mastering theory or ferreting out the elements that will help guide investigation of a particular research problem.

Terminology Issues. Terminology issues arise when drawing upon theory in other fields. For example, in applying organizational information processing theory (OIPT) (Galbraith, 1973, 1977) to supply chains, Koufteros, et al. (2006) struggled with the dilemma of remaining true to OIPT by referring to “organizational subunits,” vs. reflecting the language of supply chain management by referring to "supply chain members" or "customers and suppliers." Using the language of supply chain management risked losing the connection to OIPT, however, using the language of OIPT could make the research inaccessible to the supply chain research community.

Sloppy Operationalization. A hallmark of science is its precision of key constructs. Empirical OSM researchers' tendency towards jargon (“confused, unintelligible language” (http://www.merriam-webster.com)) and definitional sloppiness causes confusion and difficulty 
generalizing their results to broader theory. For example, capabilities, distinctive competencies, competitive priorities, competitive advantages and resources are sometimes used interchangeably. Other sets of problematic terms include risk, uncertainty and complexity; collaboration, integration and strategic alliances; and fit, alignment and consensus. There are at least 15 definitions of resilience, ranging from a reactive (post-disruption) capability (Sheffi \& Rice, 2005; Christopher \& Peck, 2004) to a proactive, preventive capability (Ponomarov \& Holcomb, 2009).

Oversimplification of Assumptions. Although Occam's Razor states that, among competing theories, the one with the fewest assumptions should be selected (Gauch, 2003), it is important that simplification of assumptions does not compromise analysis and results. Much OM research builds upon the implicit assumption that relationships are linear, for example, implying that, as the number of suppliers is reduced, performance should improve. Yet, an inverted-U relationship is more realistic; too many or too few suppliers can adversely affect performance (Choi \& Krause, 2006). In another example, some operations strategies are failure preventers (a step function), while others are success producers (an exponential relationship) (Varadarajan, 1985). Relaxing the assumption of linearity can lead to exciting theoretical developments, such as order winners and order qualifiers, which follows a step function (Hill, 2000).

Generalization to a Different Unit of Analysis. Unit of analysis issues are challenging when applying theory that was originally developed for a different field. Many of the areas from which OSM researchers borrow theory focus on individuals, while OSM research focuses primarily on firms, raising generalizability issues (Yukl \& Falbe 1991). For example, there is a strong theoretical foundation on power in the organizational behavior literature, where it is viewed as a manager's personal characteristic (Tannenbaum, 1968). However, supply chain power is a characteristic of the relationship between a source and target firm (Sullivan \& O’Connor, 1985). 
The behavioral research on intraorganizational power primarily focuses on communities of governmental, political, recreational and religious organizations that do not necessarily engage in economic interaction (Hickson et al. 1971), so its applicability to supply chain power is limited. Thus, there is a question of whether the theory base on individual power base can be extended to the independent, yet interdependent, members of a supply chain (Huo, et al., 2017).

\section{Theory Validation Opportunities}

Although there are many issues with OSM theory validation research, there are also a number of means for remedying them.

Broader Perspectives. Huff's (2009) description of scholarship as a conversation is useful in finding relevant theory to guide a theory validation project. Clues about a relevant theoretical conversation can be found in biographical information about scholars, association sites, informal interactions at conferences, co-citation in formal publications, being open-minded about the potential applicability of theories from other disciplines, staying alert to new developments at conferences and so forth. The research diamond suggests reflection upon the research question, then actively seeking an appropriate theoretical lens, trying several alternative theories before deciding which is the best fit. This process necessarily involves making challenging decisions about unit of analysis and terminology adoption vs. adaptation issues.

Go to the Source. In developing a meaningful research question using deductive reasoning, we have found tremendous value in returning to the source, reading the original exposition of a theory. Subtleties and nuances that other researchers may have not noted can be potentially useful in providing an effective theoretical lens. We have found this to be very helpful in moving beyond superficial application to actively working the bread dough of a theory. 
Consider Behavioral Theories. Moving beyond economics-based theories can open a new window of potentially relevant theoretical lenses to OSM empirical researchers. Behavioral theories view decision making as a social process influenced by the actions of others. Because it is people who ultimately make OSM decisions, constructs such as bounded rationality, routines, aspirations, satisficing, trust and selective perception are important. Behavioral theories provide a useful and exciting complement to economic theories (Bendoly, et al., 2006; Hill, et al., 2009; Crosen, et al., 2013; Riedel, et al., 2013) by taking the perspective that people are not the rational, economically-driven operators that economics-based research assumes (Tversky \& Kahneman, 1971). Rather, they are satisficers (Bromiley, 2005; Simon \& Newell, 1972), who search available alternatives until an acceptable threshold has been met.

Positive Positioning. Theory validation research should be a no-lose proposition, rather than a source of fear that the research will be a failure if the hypotheses are not supported. If a strong theoretical foundation is used as the lens, then all potential outcomes should be equally attractive. On the one hand, if a well-accepted theory is found to be relevant to a new context, this is interesting and provides further validation of the theory. On the other hand, if it is found to not be relevant in a different context, this is perhaps even more interesting. Rather than feeling defeated, researchers should instead regard this situation as an opportunity to make a unique contribution to the scientific knowledge about the relevance of a theory in various contexts.

Competing Theories. Another win-win use of theory is to frame a research problem in terms of competing theories. Because of the imprecision inherent in the social sciences, there can be alternative theoretical explanations for the same research problem. For example, Hui, et al. (2004) tested whether two-factor theory or fairness heuristic theory was a better fit for quality management. Testing competing theories provides a powerful and interesting foundation for low- 
risk research; the results will inevitably support one theoretical explanation better than the other, ensuring a positive outcome.

\section{Theory Development}

Because theory development seeks to propose new constructs or relationships between them to modify or develop new theory, it is well aligned with qualitative data, collected via interviews (Samson \& Gloet, 2014; Laihonen \& Pekkola, 2016; Sezen, et al., 2012), observation and engaged approaches (Touboulic \& Walker, 2016) such as action research (Ross, et al., 2007; Danese \& Vinelli, 2004; Baker \& Jayarama, 2012; Carvalho, et al., 2014). It uses an inductive approach, building on an interpretivist perspective (Huff, 2009), where meaning is linked to specific observations in specific settings. Thus, theory development uses the research diamond in a different way than theory validation. Rather than beginning with a research question supported by theory and using it as the basis for designing the data collection and analysis strategy, theory development begins with data collection. Through various analytical approaches that are frequently qualitative, themes emerge, which are the basis for developing new constructs, proposing new ways in which constructs are related and using them to modify existing theory or develop new theory. Inductive approaches are based on listening to the story that the data tells, which can be challenging for researchers who are accustomed to using a deductive approach to approach data based on a predetermined theoretical framework. Inductive approaches are also appropriate for taking an initial cut at big data (e.g. Shah \& Liu, 2006), helping to avoid becoming distracted by its volume and variety of constructs.

\section{Theory Development Issues}

Lack of Theory Development. Theory development can seem intimidating, especially in a field such as OSM, where theory is primarily borrowed from other fields. What is called theory 
development in OSM frequently isn't. Pointing out the limitations to a theory's range of application is not sufficient to make a theoretical contribution (Whetton, 1989; Weick, 1995; Hambrick, 2007; Sutton \& Staw, 1995). When research positioning focuses primarily on questions of what and how a proposition may be improved or another construct added, this doesn't develop new theory. Similarly, a focus on questions related to who and where simply apply an old theoretical model in a new setting.

Making a theoretical contribution lies in the whys (Whetton, 2009), which are the theoretical glue that holds a model together, specifying the dynamics that underlie a model and providing a compelling case for why they should be believed. While the whys are the most fruitful avenue for theory development, they can also be the most challenging (Whetton, 2009).

Inappropriate Application of Deductive Reasoning. Theory validation is inherently backward-facing as it applies deductive reasoning to move from abstract concepts to empirical testing. Because of this, the best that can be expected from theory validation is validation of existing theory. While this may be appropriate in some contexts, it is not appropriate for research that seeks to reveal new insights and develop theory. Rather, inductive approaches are appropriate when the goal is theory development. These require the use of different data collection and analysis strategies (Eisenhardt, 1989; Miles, et al., 2014; Yin, 2013). For example, grounded theory (Glaser \& Strauss, 1967) employs the following steps:

- Extensively describe a situation, without using specialized academic vocabulary

- Code the description to create first-level substantive categories

- Modify and improve the codes, as additional data is collected, categorized and compared.

- Conclude empirical observations when further new categories are not required to account for further observations 
Theoretical insights emerge as the categories stabilize and their relationships become apparent. Examples of OSM research employing grounded theory include Dowlatshahi (2005), Chiarini and Vagnoni (2015), Narasimham et al. (2015) and Binder and Clegg (2006).

Unnecessary Model Complexity. The models that empirical OSM researchers develop are often overly complex, with a large number of constructs and proposed relationships between them. This can make it very challenging to fully explain each of the whys within page limitations. In other fields, theoretical models are often simpler, containing only a few constructs. This allows each construct to be thoroughly developed and the why behind each proposed relationship to be strongly justified. Parsimonious, well justified theory is preferable to complex, superficial theory, however, this may require a mindset change among researchers and reviewers.

Unnecessary Model Symmetry. In developing theoretical models, OSM researchers seem to have a preference for symmetry. However, a model should only be symmetric if there is theoretical justification. For example, if there is no justification for the assumption that customers and suppliers will perceive a focal firm's power in the same way, then the model shouldn't be symmetric. This is related to our previous statements about complexity; if a relationship (link) can't be clearly theoretically justified, then it shouldn't be included.

Restriction to Macro Perspective. Most OSM research focuses on the macro (plant or firm) level of analysis (Rothaermel \& Hess, 2007). The implicit assumption that firms at the same level will perform in similar ways often results in a performance paradox, where two firms that are seemingly identical at the macro level exhibit very different performance patterns. This phenomenon is supported by the mixed findings of research that indicates some firms have significantly benefited from developments such as MRP (Orlicky, 1976), TQM (Ebrahimpour, 1985), Six Sigma (Delsanter, 1992), or Lean (Krafcik, 1988), while other similar organizations 
have not (e.g., Voss, 1992; Bhasin \& Burcher, 2006). This suggests that macro level theories may not be sufficient to explain differences in OSM performance. Ployhart et al. (2006) noted that, while lower-level constructs are formative of the higher-level constructs, this logic does not work in reverse; the presence of a high-level construct does not uniquely identify the micro-level state. This implies that macro-level observations do not reveal much about the micro level, and thus may not be a useful basis for theory in predicting future results.

\section{Theory Development Opportunities}

Apply Graphic Modeling. The results of theory development are often displayed in a graphic model, using boxes and arrows to portray relationships. A good theory should be parsimonious enough that it can be concisely described using a graphic model, yet rich enough that it requires textual discussion to explain it (Whetton, 2009). OSM graphic models often fail to serve as a foundation for construction of theoretical propositions that can withstand logical and empirical scrutiny.

Table 5 summarizes guidelines for developing effective theoretical constructs, either focal or complementary, in order to increase the precision of terminology and comparability of OSM theories. In developing a graphic model, it is useful to record a textual explanation for each arrow, ensuring that only those that are associated with theoretical explanations are included. Once the focal and complementary constructs have been identified and described in a simple $\mathrm{X} \rightarrow \mathrm{Y}$ proposition, more complex propositions can be developed (see Table 3). Note that only the side of the proposition that contains the complementary construct is expanded (Whetton, 2009), in order to ensure that the focal construct isn’t downgraded or diluted. Before finalizing a graphic model, it is useful to draw an oval around it and add relevant assumptions around the perimeter. Contextual assumptions delimit the conditions under which a theoretical model holds (Whetton, 2009), while 
conceptual assumptions help differentiate between scholarly conversations (Huff, 2009), for example, behavioral versus economic perspectives of an OSM issue.

\section{Insert Table 5 About Here}

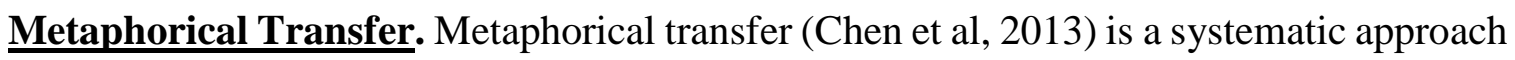
to developing theory by transferring understanding from a better-known source phenomenon to a lesser-known target phenomenon. A theory-constitutive metaphor (Boyd, 1993; Morgan, 1980) is different from a casually invoked metaphor, such as the rocks and river metaphor. For example, Chen et al. (2013) used divorce as a theory-constitutive metaphor for dissolution of a supply chain relationship, drawing upon the sociological literature on divorce theory. Conceptual equivalence is established through translation of knowledge from the domain of the source phenomenon (sociological principles of divorce) to the domain of the target phenomenon (supply chain relationship dissolution) at various levels of abstraction. At each level, lower level insights are refined through many-to-one transformations (Chen, et al., 2013), retaining only key elements that link the source and target phenomena (Garud \& Kotha, 1994).

Ontology, the lowest level of abstraction, is the logical correspondence between key elements of the source and target phenomena (Tsoukas, 1991; Garud \& Kotha, 1994), illustrated in Figure 2, generating the whats of the theory (Whetton, 1989). Analogy, the middle level of abstraction (Tsoukas, 1991; Garud \& Kotha, 1994), develops correspondence between relationships among elements of the source and target phenomena (Chen, et al., 2013). Relationships address the hows of the relationship among the ontological whats (Whetton, 1989). Establishment of equivalence at the ontological and analogical levels leads to the emergence of more generalizable principles (the identity level of abstraction) (Tsoukas, 1991; Garud \& Kotha, 
1994). Chen et al. (2013) matched semantically equivalent divorce terminology with supply chain relationship dissolution terminology to establish propositions about the relationships.

Insert Figure 2 About Here

Shifting Perspectives. Theory development can sometimes be enhanced by shifting perspectives. Examining a research problem from both micro and macro perspectives can provide a richer understanding of the why behind a theoretical model, causing the emergence of new insights (Aguinis et al., 2011; Rousseau, 2011). For example, although top management may spearhead an initiative such as Lean, it is ultimately implemented by individuals (Rothaermel \& Hess, 2007). Thus, macro effects give rise to situational mechanisms, which, in turn, influence micro level actors (individuals). While macro effects are related to performance, micro actions are taken by individual decision makers who are influenced both their preferences (e.g., for risk, uncertainty, time horizons) and macro effects. Micro forces contribute to action-formation mechanisms that, over time, result in decisions that can transform a firm (Anderson et al., 2006), illustrated in Figure 3. Thus, individual decisions, when aggregated, can impact macro performance (Hayes \& Wheelwright, 1981). By linking action-formation and transformational mechanisms, a theory will exhibit "methodological holism" (Kieser, 2015) that is lacking when micro and macro factors are considered independently (Moliterno \& Mahony, 2011); "all...research...must move back and forth between macro and micro levels to show how the macro-level changes occurred” (Coleman, 1986: 1323).

Insert Figure 3 About Here

\section{Data Collection}


The data collection strategy provides evidence of the trustworthiness and significance of the claims made by a research study (Huff, 2009). It should help to make what has been discovered more plausible to readers, reassuring the target audience that the research is trustworthy.

For theory validation research, the data collection strategy should flow from the research problem and theoretical lens. It consists of sample selection, design of data collection instruments, designation of independent and dependent variables, and procedures for collecting data (Shadish, et al., 2011). On the other hand, for theory development research, the data collection strategy is often deep immersion in a single or a few firms. Data is collected through experiencing the context as a participant, interviews, focus groups, archival data and other sources that provide rich detail about a firm. While there may be a data collection plan and structured data collection instruments, data collection for theory development is more opportunistic, building on whatever sources of relevant data are available.

\section{$\underline{\text { Issues }}$}

Sacrificing Relevance for Rigor. The effort to tightly control all aspects of data collection may cause research to lose its connection to the real world. The result, while rigorous and elegant, is imminently forgettable. This illustrates an unbalanced perspective, where data collection takes priority over the research problem, theoretical lens and data analysis.

Sacrificing Rigor for Relevance. On the other hand, relevance doesn't compensate for lack of rigor. "When it comes to empirical research, being interesting cannot substitute for a lack of validity (Bartunek, et al., 2006)." "Claims unsupported by thorough academic research, no matter how intriguing they may sound, ... are not relevant. Actually, I fear they could be dangerous (Vermeulen, 2005).” This also illustrates an unbalanced perspective, where the research problem 
takes precedence over the theoretical lens and data collection and analysis strategies. Thus, balance among the four points of the research diamond is critical.

Assumption of Similarly Motivated Respondents. Theory validation research is often designed as though all respondents shared the same motives, ignoring individual differences in background and motivation. Capitalizing on this, Westphal, et al., (1997) were able to leverage their finding that early adopters of TQM were economically driven while later adopters were institutionally driven into a paradox, creating an interesting research study that explicitly examined the motives of all respondents.

Threats to Validity. Table 6 summarizes validity concerns related to empirical research (Shadish, et al., 2011), relevant to both theory validation and theory development research. Threats to validity provide an alternative explanation for why an observed effect occurred, thus, they are relevant to data collection strategy design.

Internal validity deals with the validity of the measurement sample and methods, while external validity is related to generalizability of the results beyond the sample (Shadish, et al., 2011). Experimental studies are high in internal validity because of their tight control over extraneous effects, but are weaker in external validity, because of their artificial setting and manipulations. On the other hand, grounded theory research is higher in external validity, but often suffers from internal validity concerns.

Construct validity is the accuracy with which a measure captures the essence of a construct (Shadish, et al., 2011), and most OSM researchers routinely assess the construct validity of survey measurement scales. However, construct validity is also a critical issue for archival data sources. Because measures are limited to what is available within an archival dataset, researchers must use proxies to measure constructs of interest, which may only weakly represent it. For example, 
absenteeism is sometimes used as a proxy for job satisfaction. While low levels of job satisfaction may, indeed, result in higher absenteeism, there are potentially many other contributors. Careful operationalization of constructs through proxies is critical to ensuring construct validity of archival research studies.

Statistical conclusion validity is related to the assumptions upon which statistical methods rest (Shadish, et al., 2011). Inaccurate effect size estimation is particularly common in OSM research. Researchers may neglect the need to compensate for the increased likelihood of a Type I error as the number of hypotheses that are tested increases, leading to potential inaccurate effect size estimation in light of the complexity of many OSM models. Omitted variable bias arises in cross-sectional survey research when the error term is correlated with one of the independent variables, leading to endogeneity concerns.

Insert Table 6 About Here

Omitted Variable Bias (Endogeneity). Omitted variable bias usually arises because an important independent variable was omitted because empirical data was not available to measure it (Hamilton \& Nickerson, 2003). For example, assume that the model for $y$ is:

$$
y=\alpha+\beta_{1} x+\beta_{2} z+\varepsilon_{1}
$$

However, if empirical data to measure $z$ is not available, $\S_{2} z$ is dropped from the model and absorbed into $\mathcal{E}$. The new model is then:

$$
\begin{gathered}
y=\alpha+\beta_{1} x+\varepsilon_{2} \\
\text { Where } \varepsilon_{2}=\beta_{2} z+\varepsilon_{1}
\end{gathered}
$$

Therefore, if $x$ and $z$ are correlated, then $x$ will be correlated with the new error term $\varepsilon_{2}$, thus violating two of regression analysis’ assumptions (Wooldridge 2015; Johnston \& DiNardo, 1972):

- The error term is independently distributed and not correlated with any of the independent variables

- $x$ is deterministic, therefore, uncorrelated with the error term. 
This leads to endogeneity, which can cause the standard error of the coefficient to be biased, leading to an incorrect significance test results and, ultimately, to false conclusions.

Difficulty in Obtaining Survey Data. Survey data collection has become increasingly difficult to obtain as the popularity of surveys has increased as an OSM data collection strategy. Managers who regularly receive survey requests may believe that they interfere with their work or feel burned out. The availability of potential survey respondents also seems to be related to the state of the economy; in tough economic times, there seems to be a greater reluctance to participate in survey research. This may be related to unwillingness to disclose sensitive data, the need for organizations to operate with a leaner staff or a host of other reasons.

New Sources of Respondents. There has been increasing use of non-traditional means for obtaining survey respondents and experimental subjects, including Amazon’s Mechanical Turk (mTurk), Qualtrics and other sources that solicit respondents electronically and compensate them for their responses. These methods are associated with fast data collection in the desired sample size, offering substantial benefits for researchers. However, there is an issue of alignment with the research problem. While mTurkers are perhaps appropriate for research on general consumer behavior and attitudes, they seldom have OSM experience. Further, many mTurkers are professional survey respondents, whose commitment to carefully considering survey items may be suspect.

Single Respondents. Cross-sectional survey research that relies on a single respondent per firm suffers from validity issues, since individual responses can be biased by personal feelings, opinions, behaviors and the informant's length of tenure, level of position and job satisfaction (Bagozzi, et al., 1991) that would average out over multiple respondents. The single respondent may be rationalized as a key informant (Kumar, et al., 1993), who is knowledgeable about issues 
at an organizational level and able to generalize about intraorganizational patterns of behavior, however, the validity of this approach is questionable (Frohlich, 2002; Larson, 2005; Melnyk, et al., 2012). Because key informants are asked to perform complex judgments, such as making inferences about macro level phenomena and aggregating across people, tasks, functions and events, there is more than the normal amount of random error. Other factors contributing to variability in key informants' judgments are related to difficulties of observation in large or complex firms, breadth of information sources and volatility of changes. This is further complicated in a supply chain, where decisions are the result of actions made by a firm, its customers and suppliers (Rothaermel \& Hess, 2007).

Survey Translation Issues. The amount of non-U.S. OSM survey research has grown dramatically in recent years. Although most researchers understand the importance of using established scales, the vast majority of existing measurement scales were originally written in English. This gives rise to two important questions (Tsui, 2006).

First, should measurement scales be translated? The indigenous psychology movement, which challenges U.S. domination in conceptual frameworks, calls for development of measures based in local cultural realities, considering the unique aspects of the target culture (Behling \& Law, 2000). However, this approach limits the comparability of findings and restricts generalizability.

Second, is it possible to accurately translate measures, due to semantic equivalence issues across languages, where the same word may exist in both, but with subtle differences in meaning? For example, the word "dúvida” means both "question” and “doubt” in Portuguese. When Brazilians say that they have a doubt, Americans may interpret this as skepticism, while what is meant is simply that they have a question. In some cases, there may be no equivalent word in the 
target language; for example, there is no equivalent to the English "skill-based pay" in many languages. A second issue is the lack of conceptual equivalence across cultures. Concepts may exist independent of the actual words used to represent them. Finally, there may be a lack of normative equivalence across cultures. Norms, such as willingness to discuss certain topics, the way in which ideas are expressed and how strangers (such as researchers) are treated, can have important implications for data collection (Behling \& Law, 2000), particularly in a face-to-face situation such as an interview or focus group, potentially compromising the results.

\section{Opportunities}

Control for Endogeneity. Since endogeneity results from missing variables, the best way to control for it is in the research design, ensuring that empirical data for the potentially missing variable is collected or considering other important independent variables for which data is available. When this is not possible, the use of an instrumental variable provides a way to address endogeneity. Continuing with the example from above, a variable that is correlated with $x$, but not with $\mathcal{E}$ (known as an instrumental variable w) would need to be found. Two-stage least squares could then be used to develop an understanding of which part of the independent variable $x$ is correlated with the error term and which part is not. In the first stage, $x=\lambda+\beta_{3} w+\varepsilon_{3}$ in order to estimate $\hat{x}$, which is then used in the second stage regression: $y=\alpha+\beta_{1} \hat{\mathrm{x}}+\tilde{\varepsilon}$. The new estimate of $x$ should be uncorrelated with $\tilde{\varepsilon}$.

New Sources of Archival Data. There has been an increasing number of OSM papers that use archival financial data, due to its convenience and perceived objectivity. Depending on the research problem and the ability to address construct validity issues, archival financial data may be very appropriate. For example, event study approaches have been used to understand the stock price impact of events such as supply chain glitches (Hendricks \& Singhal, 2003), environmental 
management program implementation (Klassen \& McLaughlin, 1996; Lo, et al., 2012), technological product innovation (Xin, et al., 2010), ISO certification (Lo, et al., 2009; McGuire \& Dilts, 2008), winning a quality award (Hendricks \& Singhal, 1996) and product recalls (Thirumalia \& Sinha, 2011; Ni, et al., 2016).

Other sources of archival data may be more relevant to OSM research problems. ERP systems store a substantial amount of data about demand, inventory, lead time, delivery time and other important OSM factors. Sensors collect manufacturing data from assembly lines, uploading it to a central database as frequently as once per minute (Li \& Wang, 2017). Over-the-road trucks transmit location information up to five times per second, using embedded computers and modems (van der Spoel, et al., 2017). RFID can be used to track cartons or products as they move within a warehouse. Sustainability performance is measured by meters that monitor utilities, effluents and energy use; for instance, a meter can measure how much energy a steam generator uses, the amount produced in a steam plant and the amount used on each line, allowing management to continuously extrapolate the amount of steam lost throughout a plant. Such data may provide better OSM construct validity than financial data.

Big Data. Big data (BD) aggregates different databases to be applied simultaneously, in support of business decisions (Putka \& Oswald, 2017). It has developed from the advent of new technologies, such as the Internet of Things (IoT), social media, RFID, and the Internet. While firms continue to invest in BD analytical tools (Short \& Todd, 2017), many still struggle with extracting important insights from their BD repositories. BD is an exciting potential data source for OSM research because it is routinely collected as part of normal operations, and much of it does not suffer from the sensitivity of financial data. BD is characterized by the following traits (McAbee, et al., 2017): 
- Volume: There is a very large number of cases and variables per case. The size of BD datasets often exceeds the capability of conventional analysis software, like SPSS and SAS.

- Velocity: BD is generated, processed and made available for use at a high rate of speed. For example, Walmart processes more than 2.5 petabytes of transactional data per hour.

- Variety: BD is stored in structured, semi-structured (e.g., email) and unstructured (interviews, pdf files, Word documents, audio files, images, videos) formats.

- Veracity: The veracity of BD may be questionable, with construct validity implications. Like a simulation model, what is programmed into an IoT device is what you get.

One of the biggest challenges of working with $\mathrm{BD}$ is the substantial amount of extraneous data.

Because $\mathrm{BD}$ is collected to meet a firm's needs, rather than a researcher's needs, inductive approaches are often more useful than deductive approaches in revealing the story that BD is telling and using it to develop theory. Quantitative analysis is used to explore the data, allowing themes to emerge and guide theory development.

Thick Data. Thick data (TD) gives researchers a better understanding of the information underlying BD and can be an integral data source for theory development. While BD has hundreds of thousands of observations from different parts of a firm, TD contains fewer observations, but greater variety of information for each. For example, a motor carrier's data about a shipment from Los Angeles to New York includes the expected and actual departure time, expected and actual arrival time, truck size, departure and arrival location information, truck type (specialized or general purpose), and exception codes for issues encountered along the way. BD would contain all observations for all loads on all of a motor carrier's trucks over time, so there could be a million observations with 20 or so columns accumulated in a few months. TD would have many more columns and include non-digital, as well as digital, information; for example, it could include truck drivers' accident reports. This type of data can also be important to OSM researchers, for example through analysis of online customer reviews, using a web crawler (Chong, et al., 2017), or YouTube product reviews posted by first adopters. In manufacturing, microphones on assembly 
lines capture data in the form of words spoken by front line workers, which can be transcribed and combined with production data to better understand quality-related issues.

Align Translation Approach with Assumptions. Farh, et al. (2003) describe four approaches to survey translation issues, summarized in Table 7, based on assumptions about whether a construct is universal or specific to a culture and the availability of a high quality source language scale. It provides a guideline to alternatives for measuring a construct in a target culture and the strengths and weaknesses associated with each.

\section{Insert Table 7 About Here}

\section{Data Analysis}

The data analysis strategy is the way in which quantitative and qualitative empirical data is analyzed, in order to allow drawing valid conclusions. It consists of statistical procedures for theory validation and structured methods for analyzing qualitative data and conducting inductive analysis for theory development. Table 8 provides an overview of types of analysis methods, summarizing the strengths and weaknesses associated with each. There is no analytical silver bullet to ward off all potential criticisms. Rather, it is important to select an analytical approach that is consistent with the research problem, theoretical lens and data collection approach, building on its strengths, while acknowledging its weaknesses.

Do not 'fall in love' with the methods you currently use. Understand their inevitable weaknesses, and juxtapose your results with compensating observations from other projects that you or others carry out (Huff, 2009, p. 187).

Insert Table 8 About Here

\section{$\underline{\text { Issues }}$}

Weak Inference. The typical theory validation approach involves testing propositions against empirical data (Mantere \& Ketokivi, 2013); if there is a significant result, the study is 
considered a success. The problem of weak inference exists when a researcher has a vested interest in obtaining the hypothesized results. It is sometimes manifest in a penchant for data transformation, "torturing” the data by applying various transformations until it yields the desired results. Weak inference can cause researchers to lose sight of what the data is actually telling them. Unexpected results may have been due to a data entry or analytical error, or perhaps an outlier. More interestingly, the expected results may not have materialized because there were other forces at work. For example, Richie and Melnyk (2012) initially approached analyzing data about CTPAT (Customs-Trade Partnership Against Terrorism) certification based on Westphal et al. (1997), becoming frustrated when the data didn’t support the hypothesis that early C-TPAT adopters would be economically driven, while later adopters would be institutionally driven. They applied ever more sophisticated transformations, but continued to obtain the same results. Only when they realized the need for allowing the data to tell its own story did they understand that the bulk of C-TPAT's benefits were captured by the public, rather than participants in the principal dyad.

Predictable Data Analysis. Many survey researchers apply the same popular analytical approaches, however, the need for rigor doesn't dictate the same approach for every research problem. This may result from a perception that, if a research problem isn't amenable to SEM, the resulting paper will have reduced chances of being published in a high quality journal. According to the Law of the Instrument, "Give a small boy a hammer, and he will find that everything he encounters needs pounding" (Kaplan, 1964, p. 28), restated by Maslow (1966, p. 15) as "I suppose it is tempting, if the only tool you have is a hammer, to treat everything as if it were a nail.”

SEM has become a methodological hammer. This isn't surprising, since researchers have similar training, and it is natural that reviewers are comfortable with manuscripts that use a familiar 
analytical method. However, it can lead to methods convergence; it is like ordering the same entrée every time you visit a particular restaurant. Although tasty at first, after some point it becomes boring. OSM theory validation research is full of hammers in search of nails and researchers in search of problems that will allow them to demonstrate their prowess with a particular analytical method. Rather than starting with an analytical hammer looking for a nail, researchers should start with an interesting and important research question, use a theoretical lens to develop appropriate hypotheses, then investigate them using the most appropriate methods.

Analysis of Unstructured Data. While structured BD, such as machine downtime or retail transaction data, can be easily analyzed once volume issues have been resolved, unstructured textual data, such as customer sentiment reflected in tweets or engineering reports on maintenance problem resolution can be much more difficult to analyze through conventional methods. Machine learning, inductive analysis tools and active researcher interaction with the data may be required.

\section{$\underline{\text { Opportunities }}$}

Alignment with Research Problem. The data analysis strategy should be aligned with the research problem, rather than driving it. For example, survival analysis is appropriate for point-intime-based research problems, identifying factors influencing time-to-event decisions (Lee \& Whitmore, 2010) and quantifying the time until a dichotomous event, based on a hazard function (Kaplan \& Meier, 1958). Time series analysis is aligned with identifying elements that occur over time. For example, Melnyk, et al. (2014) used modified outlier detection to assess the impact of a supply chain disruption on various system traits. There are many other analytical methods that hold potential for empirical OM researchers and are aligned with different types of research problems, including structured case analysis (Voss, et al., 2002; Eisenhardt, 1989; Glaser \& Strauss, 1967; McCutcheon \& Meredith, 1993; Barratt, et al., 2011), behavioral experiments 
(Bendoly, et al., 2006; Perdue \& Summers, 1986), action research (Altrichter, 1993; O’Donoghue, 2003), engaged research (Touboulic \& Walker, 2016), linguistic analysis (Bach \& Robert, 1982), meta-analysis (Borenstein, 2013; Mackelprang \& Nair, 2010; White, 1996), event studies (MacKinlay, 1997; Brown \& Warner, 1985), lab research and longitudinal methods (Diggle, et al., 2013; Menard, 2007). Researchers should strive to develop a broad awareness of a variety of analytical procedures and a rich methodological toolkit.

Data Visualization. Various forms of visual display are useful in visualizing BD, in order to allow its story to emerge (Börner, 2010), offering exciting opportunities to OSM researchers. For example, geospatial visualization examines data trends based on geography. Researchers can use street maps or larger infrastructural elements to analyze the implications of various supply chain decisions, overlaid with additional information such as traffic and delays, to help explain and prevent supply delivery delays. Permanent and programmable video dashboards display data for inductive analysis. Video dashboards can display current performance of dynamic BD against targets and other information about how a plant is performing and where attention is needed.

Alignment of Visualization with Research Question. When addressing research questions related to what, data is best presented in charts, tables, or figures, such as a word cloud, where software analyzes the words in a textual document and displays them, giving more prominence (size) to words that appear more frequently. Tables summarize large datasets relatively compactly by grouping different categories. Figures show different topics and their importance, using graphical sizes or color representations to differentiate the data. Questions of where address research problems related to where products or customers flow. Geospatial maps are useful for these types of data. Global maps visually display a firm's global supply chain or how widely its raw materials are sourced, in order to identify potential trouble areas. Country maps can show 
demand for a firm's products in different states, in order to enhance product delivery. Local maps are useful in routing last-mile delivery trucks, in order to reduce delays. Research problems related to when describe how events unfold over time. The data can be continuous, where data points are continuously gathered (such as from an electronic meter), or it can be discrete, where values are only collected at certain intervals, such as annual financial performance. Temporal graphs visualize this type of data based on time series analysis. Research problems related to whom are based on relationships between entities. Network analysis shows the relationship between different product categories and suppliers to determine overall firm dependence on specific suppliers or parts commonality across the finished goods, in order to understand the importance of specific parts or suppliers. Network analysis is also useful in linking managers to specific areas of expertise, so they can be fully leveraged when specific knowledge areas are needed.

Data Mining. One of the downsides of BD is the difficulty of examining the various relationships that can exist in the data, which can be overwhelming, given the large number of available variables. It may introduce new potential independent variables whose relationships are not be known from prior research or theory. Data mining is an analytic, inductive approach to help researchers discern the story that BD is telling (Fayyad, et al., 1996). It can inform researchers of initial relationships and help to point the direction for future research (McAbee, et al., 2017) through its automatic process for identification of patterns or relationships in the data. These relationships can then be used in more advanced analysis techniques, such as predictive analytics.

Data Virtualization. Using machine learning (e.g., IBM’s Watson), computers learn new ways of looking at data and analyzing it, without specific programming, allowing them to identify potential issues and develop predictive analytics to address problems before they become major. For instance, potential equipment breakdowns can be predicted, allowing preventative 
maintenance to be performed during downtime and reducing the probability of a machine breakdown, as well as reducing maintenance costs. This provides an exciting inductive approach to theory development.

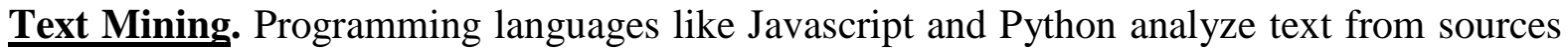
such as review websites or Twitter, using natural language processing algorithms to assess sentiment. Analysis software, such as SAS Text Miner or JMP, can then be used to examine the resulting unstructured data to identify important constructs and relationships between them, serving as a foundation for inductive theory development. Sentences are examined, assuming that words that appear in the same sentences are much more likely to be related or associated, then nouns or groups of words that form nouns to identify things that might be important are identified, as well as actions or verbs, providing researchers with an effective inductive approach to analyzing textual data.

Dark Data. Dark Data (DD) is data that exist within an organization, yet it is not examined or analyzed and thus managers do not use it to gain any insights into the firm's operations. Researchers will also need to expand their data gathering and analytical skill set to help them discover and tease apart the data that is available. Researchers might believe that firms don't have much data for analysis or that such data doesn’t exist. This might be because managers themselves might not know what data they have available or what data is collected within other units. Such data typically doesn't exist in perfectly formatted BD datasets ready for analysis and interpretation. However, such data might be “hidden” within the firm’s existing data systems. Thus, researchers need to work with managers to understand all the data that is available so they can discover such DD. DD might be difficult to extract and format in preparation for data analysis. However, DD can contain a lot of information that can provide rich insights for academics as well as managers. 
Predictive Analytics. While descriptive analytics enable a researcher to examine historical data, predictive analytics uses machine learning and predictive modeling techniques to gain insights into $\mathrm{BD}$. Combining both, the ultimate frontier is prescriptive analysis, where past $\mathrm{BD}$ is analyzed and models are predicted using simulation, resulting in data-based prescriptions. Although most OSM research uses descriptive analytics, the nature of BD changes the way that data can be examined.

\section{Conclusions}

Research is dynamic, growing and changing in response to new challenges, new research questions, new developments, new analytical and data collection methodologies and new demands from both its readers and those who hope to use it. Consequently, every so often, scholars should stop to take stock of what has happened, what is taking place, and what is likely to occur, assessing the field and its approaches, with a goal of learning, unlearning, and relearning. Through learning, researchers develop an understanding of what has worked in the past and why, learn about new opportunities and methodologies, and discover issues that are becoming critical to readers. By unlearning, through studying past research and current needs, researchers identify and discard approaches, tools, theories, and frameworks that are no longer effective. In relearning, researchers get back to the basics of research, considering critical but often overlooked fundamentals for dealing with the challenges of today's environment.

Thus, researchers should be concerned about both the past and future. As they study the past, researchers preserve and communicate effective approaches and expose those that have been less effective, so that they can be discarded. As researchers focus on the future, they identify emerging opportunities, related to issues, development of new theoretical frameworks, new 
sources of data or the advent of new methodologies, so that they can direct attention to them and recognize the challenges associated with exploiting these future opportunities.

In celebrating a significant milestone for a major OSM journal, the International Journal of Production Research, we have had the occasion to stop and re-assess OSM empirical research. We used Dickens' contrast between the best of times and the worst of times to frame our reassessment. We focused on the best of times, a future in which empirical OSM research is entering into a veritable epoch of incredulity due to exciting opportunities available in big data and other new data sources, analytical techniques like text mining, interesting and important research problems, and innovative tools for developing theory. We also explored the worst of times, focusing on the challenges and problems that are currently plaguing empirical OSM research. Our goal was to show how the worst of times can be learned from, so that OSM researchers will be poised to take advantage of the best of times. We introduced the research diamond as a vehicle for emphasizing the importance of a balanced research perspective that treats the research problem, theory, data collection and data analysis as equally important.

We do not believe that OSM survey research is dead, but rather that it is time for a serious examination of the state-of-the-art. Just as a product's life cycle can be extended by improving a product or adding new features, the life cycle of OSM survey research can be extended by incorporating new developments to improve its quality. In contrast, other empirical research methods are still in their infancy (for example, engaged research methods, such as action research, and ethnographic research) or in the growth part of their life cycle (case research, experiments, event studies). It is critical to stay in touch with the latest theoretical and methodological developments, which often takes place in other fields, in order to sustain the quality of OSM empirical research. 
By learning and addressing the issues in this period of the best of times and the worst of times, we can take advantage of the opportunities facing OSM to create and disseminate research that is balanced, insightful, rigorous, relevant, impactful and interesting. That is a challenge worthy of our field and one we believe it is ready to meet. 


\section{References}

Adam, E.E., Jr., Swamidass, P.M., 1989. Assessing operations management from a strategic perspective. Journal of Management, 15(2), 181-203.

Aguinis, H., Boyd, B.K., Pierce, C.A., Short, J.C., 2011. Walking new avenues in management research methods and theories: Bridging micro and macro domains. Journal of Management, 37(21), 395-403.

Altrichter, H., 1993. Teachers Investigate Their Work: An Introduction to the Methods of Action Research. Routledge.

Amundson, S.D., 1998. Relationship between theory-driven empirical research in operations management and other disciplines. Journal of Operations Management, 16(4), 341-359.

Bach, K., Robert, M.H., 1982. Linguistic Communication and Speech Acts, 4, Cambridge, MA: MIT Press.

Bagozzi, R.P., Yi, Y., Phillips, L.W. 1991. Assessing construct validity in organizational research. Administrative Sciences Quarterly, 36, 427-458.

Baker, T., Jayaraman, V., 2012. Managing information and supplies inventory operations in a manufacturing environment. Part 1: An action research study. International Journal of Production Research, 50(6), 1666.

Barley, S.R., 2000. When I write my masterpiece: thoughts on what makes a paper interesting. Academy of Management Journal, 49(1), 16-20.

Barney, J., Wright, M., Ketchen, D.J. Jr., 2001. The resource-based view of the firm: ten years after 1991. Journal of Management, 27(6), 625-641.

Barratt, M., Choi, T., Li, M., 2011. Qualitative case studies in operations management: trends, research outcomes and future research implications. Journal of Operations, Management, 29(4), 329.

Bartunek, J.M., Rynes, S.L., Ireland, R.D., 2006. What makes research interesting and why does it matter? Academy of Management Journal, 49(1), 9-16.

Basale, R.C. ad Bellamy, M.A. (2014). Supply network structure visibility and risk diffusion: a computational approach. Decision Sciences, 45(4), 753-789.

Behling, Orlando and Law, Kenneth S., 2000. Translating Questionnaires and Other Research Instruments: Problems and Solutions. Sage Publications, Inc., Quantitative Applications in the Social Sciences, \#133.

Bendoly, E., Donohue, K., Schultz, K.L. 2006. Behavior in operations management: assessing recent findings and revisiting old assumptions. Journal of Operations Management, 24, 737-752.

Benner M.J., Veloso, F.M. 2008. ISO 9001 practices and financial performance: a technological coherence perspective. Journal of Operations Management, 26, 611-629.

Benton, W.C., \& Maloni, M. 2005. The influence of power driven buyer/seller relationships on supply chain satisfaction. Journal of Operations Management, 23(1), 1-22.

Benzudenhout, C.N., Bodhanya, S., Sanjika, T., Silberman, M., Boote, G.L.N. 2012. Networkanalysis approaches to deal with causal complexity in a supply network. International Journal of Production Research, 7(1), 1840-1849.

Bhasin, S., Burcher, P. 2006. Lean viewed as a philosophy. Journal of Manufacturing Technology Management, 17(1/2), 56-72.

Binder, M., Clegg, B.T., 2006. A conceptual framework for enterprise management. International Journal of Production Research, 44(18/19), 3813. 
Borenstein, N., Hedges, L.V., Higgins, J.P.T., Rothstein, H.,R., 2009. Introduction to MetaAnalysis, New York: John Wiley \& Sons.

Börner, K., 2010. Atlas of Science: Visualizing What We Know. MIT Press.

Boyd, R., 1993. Metaphor and theory change: what is 'metaphor' a metaphor for? In Orotny, A. (Ed.), Metaphor and Thought, $2^{\text {nd }}$ Ed. Cambridge, UK: Cambridge University Press, 357408.

Bromiley, P., 2005. The Behavioral Foundations of Strategic Management. Madden, PA: Blackwell Publishing.

Brown, S.J., Warner, J.B., 1985. Using daily stock returns: the case of event studies. Journal of Financial Economics, 14(1), 3-31.

Campbel, J., Sankaranl, J. 2005. An inductive framework for enhancing supply chain integration. International Journal of Production Research, 43(16), 3321-3351.

Carvalho, A.N., Scarvada, L.F., Lustosa, L.J., 2014. Implementing finite capacity production scheduling: lessons from a practical case. International Journal of Production Resarch, 52(4), 1215.

Cattani, K., Gilland, W., Heese, H., Swaminathan, J., 2006. Boiling frogs: pricing strategies for a manufacturer adding a direct channel that competes with the traditional channel. Production and Operations Management, 15(1), 40-56.

Chen, Y.S., Rungtusanatham, M.J., Goldstein, S.M., Koerner, A.F., 2013. Theorizing through metaphorical transfer in OM/SCM research: divorce as a metaphor for strategic buyersupplier relationship dissolution. Journal of Operations Management, 31(7-8), 579.

Chiarini, A., Vagnoni, E., 2015. World-class manufacturing by Fiat: comparison with Toyota production system from a strategic management, management accounting, operations management and performance measurement dimension. International Journal of Production Research, 53(2), 590.

Chien, C.F., Liu, C.W., Chuang, S.C., 2017. Analysing semiconductor manufacturing big data for root cause detection of excursion for yield enhancement. International Journal of Production Research, 55(17), 5095-5107.

Choi, T.Y., Dooley, K.J., Rungtusanatham, M., 2001. Supply networks and complex adaptive systems: control vs. emergence. Journal of Operations Management, 19(3), 351-366.

Choi, T.Y., Krause, D.R., 2006. The supply base and its complexity implications for transaction cost, risks, responsiveness and innovation. Journal of Operations Management, 24(5), 637.

Choi, T.Y., \& Wu, Z. 2009. Triads in supply networks: theorizing buyer-supplier relationships. Journal of Supply Chain Management, 45(1), 8-25.

Chong, A.Y.L, Ch’ng, E., Liu, M.J., Li, B., 2017. Predicting consumer product demands via big data: the roles of online promotional marketing and online reviews. International Journal of Production Research, 55(17), 5142-5156.

Christopher, M., Peck, H., 2004. Building the resilient supply chain. International Journal of Logistics Management, 15(2), 1-14.

Clark, K.B., Wheelwright, S.C., 1993. New Product and Process Development. New York: Free Press.

Croson, R., Schultz, K., Siemsen, E., Yeo, A.L., 2013. Behavioral operations: the state of the field. Journal of Operations Management, 31(1-2), 1.

Danese, P., Vinelli, A., 2009. Supplier network relocation in a capital-intensive context: A longitudinal case study. International Journal of Production Research, 47(4) 
Davis, M.S., 1971. That's interesting! Towards a phenomenology of sociology and a sociology of phenomenology. Philosophy of Social Science, 1, 309-344.

Diggle, P. Heagerty, P., Liang, K-Y, Zeger, S., 2013. Analysis of Longitudinal Data. New York: Oxford University Press.

DiMaggio, P. J., Powell, W.W., 1983. The iron cage revisited: institutional isomorphism and collective rationality in firm fields. American Sociological Review, 48, 147-160.

Dowlatshahi, 2005. A strategic framework for the design and implementation of remanufacturing operations in reverse logistics. International Journal of Production Research, 43(16), 34553480 .

Durugbo, C., 2013. Competitive product-service systems: lessons from a multicase study. International Journal of Production Research, 51(19), 5671.

Delsanter, J.M., 1992. Six sigma. Managing Service Quality, 2(4), 203.

Eisenhardt, K.M., 1989. Building theories from case study research. Academy of Management Review, 14(4), 532-550.

Farh, J-L, Canella, A.A., Lee, C., 2006. Approaches to scale development in Chinese management research. Management Review, 2(3), 301-318.

Fayyad, U., Piatetsky-Shapiro, G., Smyth, P. 1996. From data mining to knowledge discovery in databases. AI Magazine, 17(3) 37.

Ferdows, K., DeMeyer, A., 1990. Lasting improvements in manufacturing performance: in search of a new theory. Journal of Operations Management, 9(2), 168.

Flynn, B.B., Koufteros, X., Lu, G., 2016. On theory in supply chain uncertainty and its implications for supply chain integration. Journal of Supply Chain Management, 52(3), 327.

Flynn, B.B., Sakakibara, S., Schroeder, R.G., Bates, K.A., Flynn, E.J., 1990. Empirical research methods in operations management. Journal of Operations Management, 9(2), 250-284.

Foropon, C., McLachlin, R., 2012. Metaphors in operations management theory building. International Journal of Operations and Production Management, 33(2), 181-196.

Frohlich, M.T., 2002. Techniques for improving response rates on operations management survey research. Journal of Operations Management, 20(1), 53-62.

Gailes, G., Clarke, S., Huff, J. 2009. Controversies about theory. In Huff, A.S. 2009. Designing Research for Publication. Los Angeles: Sage Publications.

Galbraith, J., 1973. Designing Complex Organizations. Reading, MA: Addison-Wesley.

Galbraith, J., 1977. Organization Design, Reading, MA: Addison-Wesley.

Gauch, H.G., 2003. Scientific Method in Practice. Cambridge University Press.

Goldratt, E. 1992. The Goal. North River Press.

Glaser, B.G., Strauss, A.I., 1967. The Discovery of Grounded Theory: Strategies for Qualitative Research. New Brunswick: Aldine, Transaction.

Granovetter, M.S., 1973. The strength of weak ties. American Journal of Sociology, 78(6), 13601380.

Garud, R., Kotha, S., 1994. Using the brain as a metaphor to model flexible production systems. Academy of Management Review, 19(4), 671-698.

Gauch, H.G., 2003. Scientific Method in Practice. Cambridge, UK: Cambridge University Press.

Hambrick, D.C., 2007. The field of management's devotion to theory: too much of a good thing? Academy of Management Journal, 50(6), 1346-1352.

Hamilton, B.H., Nickerson, J.A. 2003. Correcting for endogeneity in strategic management research. Strategic Organization, 1(1), 51-78. 
Hayes, R.H., Wheelwright, S.C., 1984. Restoring our Competitive Edge: Competing Through Manufacturing. Wiley.

Hendricks, K.B., Singhal, V.R., 2003. The effect of supply chain glitches on shareholder wealth. Journal of Operations Management, 21(50), 501-522.

Hickson, P.J., Hinings, C.R., Lee, R.E., Schneck, R.E., Pennings, J.M., 1971. A strategic contingencies theory of interorganizational power. Administrative Science Quarterly, 16(2), 216.

Hill, J.A., Eckerd, S., Wilson, D., Greer, B., 2009. The effect of unethical behavior on trust in a buyer-supplier relationship: the mediating role of psychological contract violations. Journal of Operations Management, 27(4), 281.

Hill, T. 2000. Manufacturing Strategy: Text and Cases, Boston: McGraw Hill-Irwin.

Hora, M. Hari, B., Roth, A.B., 2011. Safety hazard and time to recall: the role of recall strategy, product defect type and supply chain player in the U.S. toy industry. Journal of Operations Management, 29(7-8), 766.

Hora, M., Klassen, R.D., 2013. Learning from others’ misfortune: factors influencing knowledge acquisition to reduce operational risk. Journal of Operations Management, 31(1-2), 52.

Huff, A.S., 2009. Designing Research for Publication. Los Angeles: Sage.

Hui, M.K., Zhao, X., Fan, X., Au, K., 2004. When does the service process matter? A test of two competing theories. Journal of Consumer Research, 31(2), 465-475.

Huo, B., Flynn, B.B., Zhao, X., Supply chain power configurations and their relationship with performance. Journal of Supply Chain Management, 2017, 53(2), forthcoming.

Jensen, M., Meckling, W., 1976. Theory of the firm: managerial behavior, agency costs and capital structure. Journal of Financial Economics, 39(3), 305-360.

Jin, J., Liu, Y, Ji, P., Liu, H. 2016. Understanding big consumer opinion data for market-driven product design. International Journal of Production Research, 54(10), 3019-3041.

Johnston, J., DiNardo, J., 1972. Econometric methods. New York, 19(7), 22.

Kaplan, A., 1964. The Conduct of Inquiry: Methodology for Behavioral Science. San Francisco: Chandler Publishing Co.

Kennedy, M.T., Fiss, P.C. 2009. Institutionalization, framing, and diffusion: the logic of TQM adoption and implementation decisions among U.S. hospitals. Academy of Management Journal. 529(5), 897-918.

Kieser, W., 2015. Methodological individualism and holism: two views, one purpose. MS. Thesis, The Open University.

Klassen, R.D., McLaughlin, C.P., 1996. The impact of environmental management on firm performance. Management Science, 42(8), 1199.

Krafcik, J.F., 1088. Triumph of the lean production system. Sloan Management Review, 30(1), 41.

Kumar, N., Stern, L.W., Anderson, J.S. 1993. Conducting interorganizational research using key informants. Academy of Management Journal, 36(6), 1633-1651.

Laihonen, H., Pekkola, S. 2016. Impacts of using a performance measurement system in supply chain management: a case study. International Journal of Production Research, 54(18), 5607-5617.

Lee, M.T., Whitmore, G.A., 2010. Proportional hazards and threshold regression: their theoretical and practical connections. Lifetime Data Analysis, 16(2), 196-214.

Levitt, D.S., Dubner, S.J., 2005. Freakonomics: A Rogue Economist Explores the Hidden Side of Everything. New York: Harper Collins. 
Li, D., Wang, X. 2017. Dynamic supply chain decisions based on networked sensor data: an application in the chilled food retail chain. International Journal of Production Research, 55(17), 5127-5141.

Lo, C,K.Y., Yeung, A.C.L., Cheng, T.C.E., 2012. The impact of environmental management systems on financial performance in fashion and textile industries. International Journal of Production Economics, 35(2), 561.

Mackelprang, A.W., Nair, A., 2010. Relationship between just-in-time manufacturing practices and performance: a meta-analytic investigation. Journal of Operations Management, 28(4), 283.

MacKinlay, A.C., 1997. Event studies in economics and finance. Journal of Economic Literature, 35(1), 13-39.

Mantere, S., Ketokivi, M., 2013. Reasoning in organization science. Academy of Management Review, 35(2), 315-333.

Maslow, A.H., 1966. The Psychology of Science: A Renaissance.

McAbee, S.T., Landis, R.S., Burke, M.I. 2017. Inductive reasoning: the promise of big data. Human Resource Management Review, 27, 277-290.

McCutcheon, D.M., Meredith, J.R., 1993. Conducting case study research in operations management. Journal of Operations Management, 11(3), 239.

McQuire, S.J., Dilts, D.M., 2008. The financial performance of standard stringency: an event study of successive generations of the ISO 9000 standard. International Journal of Production Economics, 113(1), 3.

Melnyk, S.A., Page, T.J., Wu, S.J. Burns, L.A. 2012. Would you mind completing this survey: assessing the state of survey research in supply chain management. Journal of Purchasing and Supply Management. 18, 35-45.

Melnyk, S.A., Zobel, C.W., Macdonald, J.R., Griffis, S.E. 2014. Making sense of transient responses in simulation studies. International Journal of Production Research. 52(3), 617634.

Menard, S., 2007. Handbook of Longitudinal Research Design, Measurement and Analysis. Burlington, MA: Academic Press.

Miles, M.B., Huberman, A.M., Saldanha, J., 2014. Qualitative Data Analysis: A Methods Sourcebook, $3^{\text {rd }}$ Ed. Sage.

Moliterno, T.P., Mahony, D.M., 2011. Network theory of organizations: a multilevel approach. Journal of Management, 37(2), 443-467.

Morgan, G., 1980. Paradigms, metaphors and puzzle solving in organizational theory. Administrative Science Quarterly, 25(4), 605-622.

Narasimhan, R., Narayanan, S., Srinivasan, R., 2010. Explicating the mediating role of integrative supply management practices in strategic outsourcing: a case study analysis. International Journal of Production Research, 48(2), 379.

Ni, J., Flynn, B.B., Jacobs, F.R., 2016. The effect of a toy industry product recall announcement on shareholder wealth. International Journal of Production Research, 54(18), 5404-5415.

O’Donoghue, T., 2003. Qualitative educational research in action: doing and reflecting. RoutledgeFalmer.

Orlicky, J., 1975. MRP: The New Way of Life in Production and Inventory Management. McGraw Hill. 
Pathak, S.D., Day, J.M., Sawaya, W.J. and Kristal, M.M. (2007). Complexity and adaptivity in supply networks: building supply network theory using a complex adaptive systems perspective. Decision Sciences, 38(4), pp. 547-549.

Perdue, B.C., Summers, J.O., 1986. Checking the success of manipulations in marketing experiments. Journal of Marketing Research, 23(4), 317-326.

Ponomarov, S.Y., Holcomb, M.C., 2009. Understanding the concept of supply chain resilience. International Journal of Logistics Management, 20(1), 124-143.

Poole, M.S., Van de Ven, A.H., 1989. Using paradox to build management and firm theories. Academy of Management Review, 14(4), 562-578.

Powell, T.C., 1995. Total quality management as competitive advantage: a review and empirical study. Strategic Management Journal, 6(1), 15.

Putka, D.J., Oswald, F.L. 2017. Implications of the big data movement for the advancement of IO science and practice. In S. Tonidandel, E. King, \& J. Cortina. 2015. Big Data at Work: The Data Science Revolution and Firm Psychology. New York: Routledge.

Ritchie, W.J., Melnyk S.A., 2012. The impact of emerging institutional norms on adoption and timing decisions: evidence from C-TPAT - a government antiterrorism initiative. Strategic Management Journal, 33(7), 860.

Rothaermel, F.T., Hess, A.M., 2007. Building dynamic capabilities: innovation driven by individual firm and network-level effects. Organization Science, 18(6), 898-921.

Ross, A., Vaidyanathan, J., Robinson, P., 2007. Optimizing 3PL service delivery using a cost-toserve and action research framework. International Journal of Production Research, 45(1), 83.

Roth, A.V., Tsay, A.A., Pullman, M., Gray, J.V.. 2008. Unraveling the food supply chain: strategic insights from China and the 2007 recalls. Journal of Supply Chain Management, 44(1), 2239.

Rousseau, D.M., 2011. Reinforcing the micro/macro bridge: organizational thinking and pluralistic vehicles. Journal of Management, 37, 429-42.

Samson,D., Gloet, M., 2014. Innovation capability in Australian manufacturing organisations: an exploratory study. International Journal of Production Research, 52(21), 6448.

Sezen, B., Karakadilar, I.S., Buyukozkan, G., 2012. Proposition of a model for measuring adherence to lean practices applied to Turkish automotive part suppliers. International Journal of Production Rsearch, 50(14), 3878.

Shadish, W.R., Cook, T.D., Campbell, D.T. 2011. Experimental and Quasi-Experimental Designs for Generalized Causal Inference. Wadsworth Publishing.

Shah, D.Y., Liu, C.H., 2006. Development and evaluation of a tree-indexing approach to improve case-based reasoning illustrated by the due date assignment problem. International Journal of Production Research, 44(15), 11.

Sheffi, Y., Rice, J.B., 2005. A supply chain view of the resilient enterprise. MIT Sloan Management Review, 47(1).

Short, J., Todd, S., 2017. What's your data worth? MIT Sloan Management Review, 58(3), p.17.

Simon, H.A., 1979. Rational decision making in business organizations. The American Economic Review, 69(4), 493-513.

Simon, H.A., Newell, A., 1972. Human Problem Solving. Englewood Cliffs, NJ: Prentice-Hall.

Solomon, M. 2014. 2015 is the year of the millennial customer: 5 key traits these 80 million consumers share. https://www.forbes.com/sites/micahsolomon/2014/12/29/5-traits-that- 
define-the-80-million-millennial-customers-coming-your-way/\#78dd5e525e56. Accessed January 172017.

Su, H.C., Chen, Y.S., Ro, Y.K. 2017. Perception differences between buyer and supplier: the effect of agent negotiation styles. International Journal of Production Research, 55(20), 60676083.

Sullivan, G.L., O’Connor, P.J., 1985. Social power-based print advertising: theoretical and practical considerations. Psychology and Marketing, 2(3), 217.

Sutton, R.S., Staw, B.M., 1995. What theory is not. Administrative Science Quarterly, 40 (3), 371-390.

Tannenbaum, A.S., 1968. Control in Organizations. McGraw Hill.

Thirumalai, S., Sinha, K.K., 2011. Product recalls in the medical device industry: an empirical exploration of the sources and financial consequences. Management Science, 57(2), 376392.

Touboulic,, A., Walker, H., 2016. A relational, transformative and engaged approach to supply chain management: the potential of action research. Human Relations, 69(2), 301.

Tsoukas, H., 1991. The missing link: a transformation view of metaphors in organization science. Academy of Management Review, 16(3), 566-585.

Tsui, A.S., 2006. Contextualization in Chinese management research. Management and Organization Review, 2(1), 1-13.

Tversky, A., Kahneman, D., 1974. Judgment under uncertainty: heuristics and biases. Science, 185(4157), 1124-1131.

Van de Ven, A., 2007. Engaged Scholarship. Oxford, UK: Oxford University Press.

Van der Spoel, S., Amrit, C., van Hillegersberg, J., 2017. Predictive analytics for truck arrival time estimation: a field study at a European distribution centre. International Journal of Production Research, 55(17), 5062-5078.

Vermeulen, P., 2005. On rigor and relevance: fostering dialectic progress in management research. Academy of Management journal 48, 978-982.

Voss, C. Tsikriktsis, N., Frohlich, M., 2002. Case research in operations management. Journal of Operations Management, 22(2), 195-219.

Weick, K.E., 1989. Theory construction as disciplined imagination. Academy of Management review, 14(4), 516-531.

Weick, K.E., 1995. What theory is not, theorizing is. Administrative Science Quarterly, 14(3), 385-390.

Westphal, J.D., Gulati, R., Shortell, S.M., 1997. Customization or conformity? An institutional and network perspective on the content and consequences of TQM adoption. Administrative Science Quarterly, 42(2), 366-394.

Whetton, D.A., 1989. What constitutes a theoretical contribution? Academy of Management Review, 14(4), 496-495

Whetton, D.A., 2009. Modeling theoretical propositions. In Huff, A.S., Designing Research for Publication. Los Angeles: Sage, 217-247.

White, G.P., 1996. A meta-analysis model of manufacturing capabilities. Journal of Operations Management, 14(4), 315-331.

Williamson, O.E., 1975. Markets and Hierarchies: Analysis and Antitrust Implications. New York: Free Press.

Williamson, O.E., 1981. The economics of organization: The transaction cost approach. American Journal of Sociology, 87, 548-577. 
Wooldridge, J.M. 2015. Introductory Econometrics: A Modern Approach. Nelson Education.

Wu, J., Melnyk, S., Flynn, B. B. 2010. Operational capabilities: the secret ingredient. Decision Sciences, 41(4), 721-754.

Xin, J.\&., Yeung, A.L., Cheng, T.C.E., 2008. Radical innovations in new product development and their financial implications: an event study of U.S. manufacturing firms. Operations Management Review, 1(2), 119-128.

Yeung, A.C.L., Lai, K.H., Yee, R.W.Y., 2007. Organizational learning, innovativeness, and organizational performance: a qualitative investigation. International Journal of Production Research, 45(11), 2449.

Yin, R.K., 2013. Case Study Research: Design and Methods, $5^{\text {th }}$ Ed., Sage.

Yukl, G., Falbe, C.M., 1991. Importance of different power sources in downward and lateral relations. Journal of Applied Psychology, 76(3), 416. 


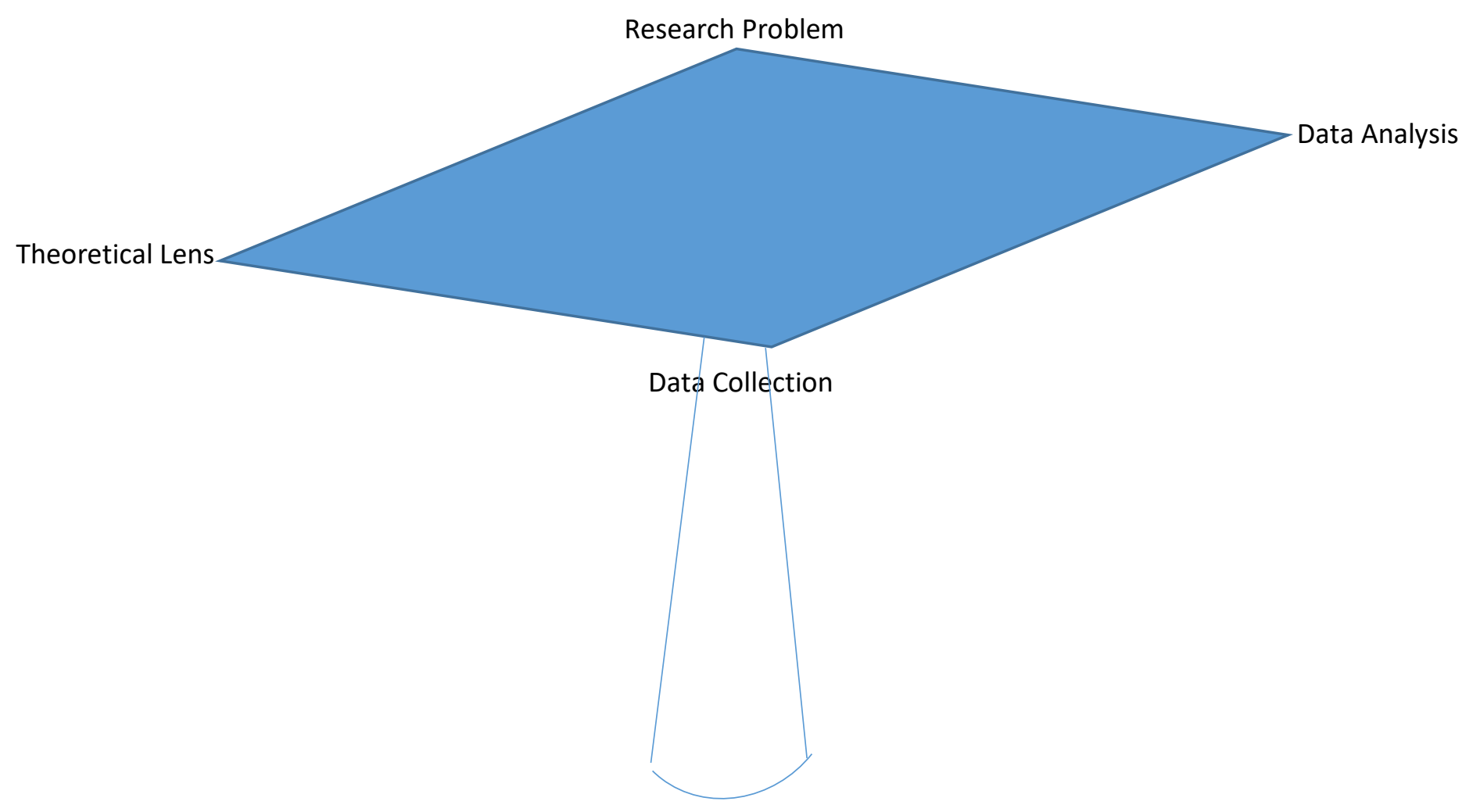

Figure 1. The Research Diamond 


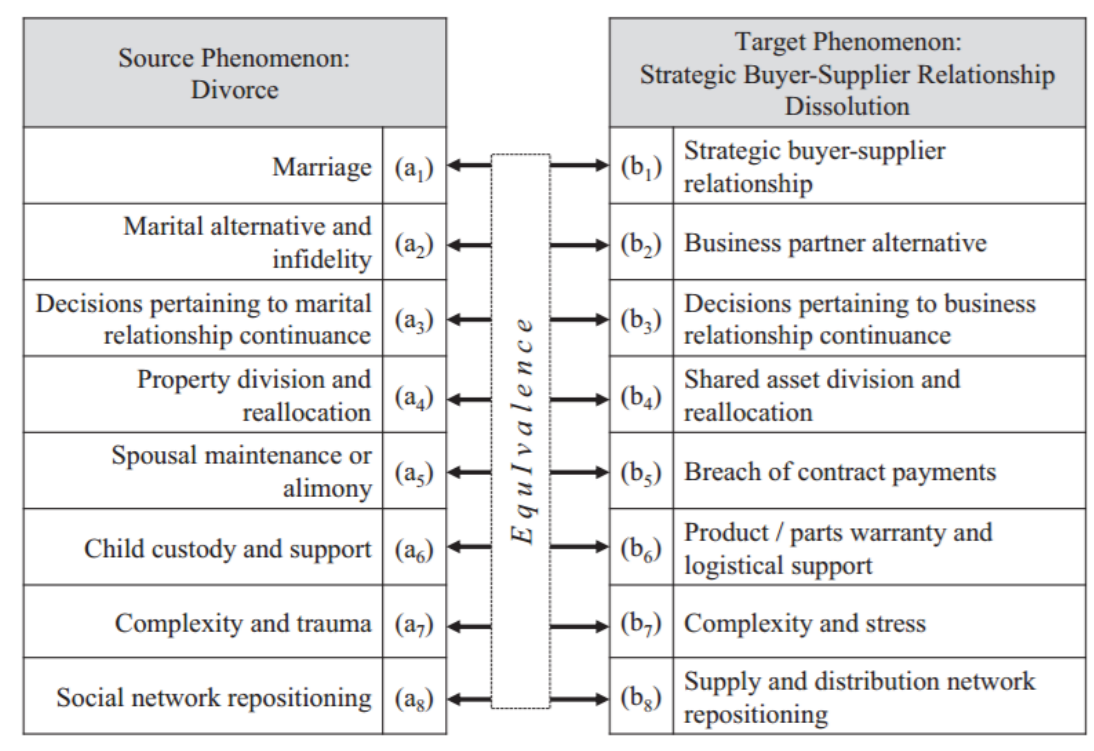

Figure 2. Example of Equivalence at the Level of Ontology From Chen, et al., 2013

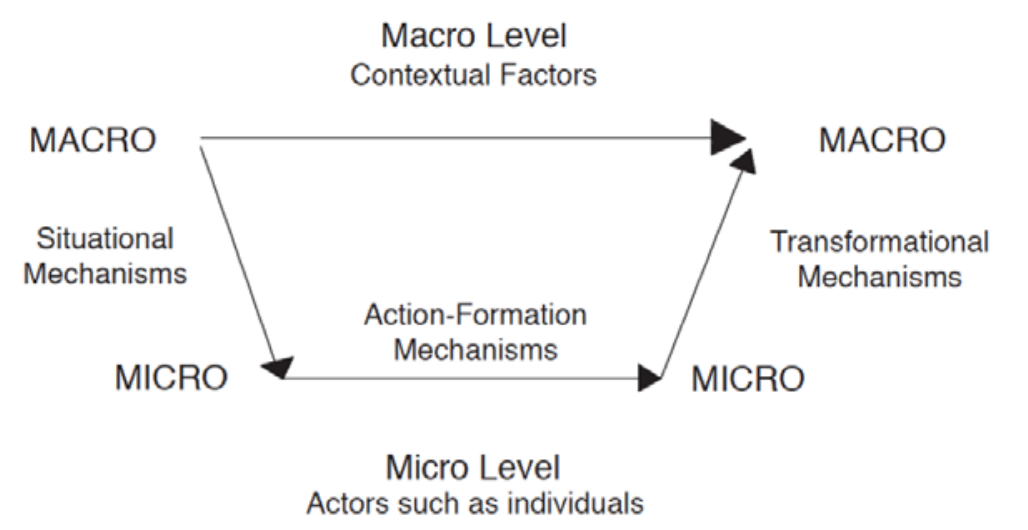

Figure 3. Relationship Between Macro and Micro Actions

Adapted from Anderson, et al.'s (2006) mechanism model 
Table 1

Types of Research Questions

\begin{tabular}{|c|c|c|c|}
\hline Type & Definition & Reader Reaction & OSM Examples \\
\hline Obvious & $\begin{array}{l}\text { Questions that don't need to be asked because their } \\
\text { answers are widely accepted or readily established } \\
\text { through logic and reasoning. }\end{array}$ & $\begin{array}{l}\text { - Of course } \\
\text { - It goes without saying } \\
\text { - Everyone knows that }\end{array}$ & $\begin{array}{l}\text { - Does lead time affect the reorder point? } \\
\text { - How is quality management } \\
\text { implemented in [fill in the country]? }\end{array}$ \\
\hline Absurd & $\begin{array}{l}\text { Challenges an entire set of assumptions, suggesting that } \\
\text { everything we previously believed to be true is actually } \\
\text { false. }\end{array}$ & $\begin{array}{l}\text { - That's crazy } \\
\text { - That doesn't make sense }\end{array}$ & $\begin{array}{l}\text { - Are economies of scale no longer } \\
\text { relevant? } \\
\text { - Decision makers are completely } \\
\text { rational }\end{array}$ \\
\hline Irrelevant & Questions whose results have little practical value. & $\begin{array}{l}\text { - So what? } \\
\text { - Who cares? } \\
\text { - Why bother? }\end{array}$ & $\begin{array}{l}\text { - What is the impact of rounding errors } \\
\text { after the } 25^{\text {th }} \text { decimal place? } \\
\text { - Do companies have different purchase } \\
\text { motivations? }\end{array}$ \\
\hline Interesting & $\begin{array}{l}\text { Questions that: } \\
\text { - } \quad \text { Challenge taken-for-granted beliefs } \\
\text { - } \quad \text { Have a practical, as well as theoretical, dimension } \\
\text { - } \quad \text { Deny some part of present practical activity } \\
\text { - } \quad \text { Depose new practical activity } \\
\text { being absurd } \\
\text { - Present an interesting spin } \\
\text { - } \quad \text { Propose a perspective that departs from the } \\
\quad \text { ubiquitous }\end{array}$ & $\begin{array}{l}\text { - That's interesting } \\
\text { - That's important } \\
\text { - I want to continue } \\
\text { reading } \\
\text { - This is really exciting }\end{array}$ & $\begin{array}{l}\text { - Does trust help or hinder a supply } \\
\text { chain relationship? } \\
\text { - Is factory focus as efficient as we } \\
\text { believe? }\end{array}$ \\
\hline
\end{tabular}


Table 2

Rock and Roll Metaphor for Interesting Research Questions

\begin{tabular}{|c|c|c|}
\hline Criterion & Definition & Example \\
\hline Uncomfortable & $\begin{array}{l}\text { The familiar, while comfortable, isn't always } \\
\text { interesting. An interesting research question should } \\
\text { move beyond what is comfortable. }\end{array}$ & $\begin{array}{l}\text { I love the Greatful Dead's music. Although it is very } \\
\text { familiar, it isn't interesting to me because I don't find it to } \\
\text { be new or unique. }\end{array}$ \\
\hline Challenging & $\begin{array}{l}\text { Seeing something as interesting and enjoying it } \\
\text { aren't synonymous. Don't be afraid to tackle } \\
\text { challenging research questions. }\end{array}$ & $\begin{array}{l}\text { While I find Nirvana's heavy metal sound interesting, I } \\
\text { don't especially enjoy listening to it. }\end{array}$ \\
\hline Important & $\begin{array}{l}\text { Being interesting doesn’t necessarily imply being } \\
\text { important. Focus on importance, rather than } \\
\text { uniqueness or filling gaps. }\end{array}$ & $\begin{array}{l}\text { Tiny Tim's falsetto “Tiptoe Through the Tulips,” } \\
\text { accompanied by a ukulele is interesting, yet imminently } \\
\text { unimportant. (If you don’t remember Tiny Tim, you will } \\
\text { be quickly convinced by this video: } \\
\text { https://www.youtube.com/watch?v=zcSlcNfThUA) }\end{array}$ \\
\hline Tacit & $\begin{array}{l}\text { There is a tacit component to being interesting. A } \\
\text { good research question has an interesting tacit } \\
\text { component. }\end{array}$ & $\begin{array}{l}\text { Nobody is able to replicate the sound of Jerry Garcia's } \\
\text { guitar playing, no matter how much they study his music. } \\
\text { The late Mr. Garcia couldn't have probably even have } \\
\text { articulated what was unique about it. }\end{array}$ \\
\hline
\end{tabular}




\section{Table 3}

Development and Improvement of Theoretical Propositions

\begin{tabular}{|c|c|c|}
\hline \multicolumn{3}{|l|}{ FRAMING } \\
\hline Focal Construct & Framing & OSM Example \\
\hline Independent variable & $\begin{array}{l}\text { Given the importance of } Y \text {, you'll be interested } \\
\text { to learn about my proposed new antecedent } \mathrm{X}_{\mathrm{a}} \text {. }\end{array}$ & $\begin{array}{l}\text { Given the importance of competitive performance, you } \\
\text { will be interested to learn about my proposed new } \\
\text { antecedent, psychological trust. }\end{array}$ \\
\hline Dependent variable & $\begin{array}{l}\text { Given the importance of } \mathrm{X} \text { in this research } \\
\text { conversation, you'll be interested to learn about } \\
\text { my proposed new consequent } \mathrm{Y}_{\mathrm{a}} \text {. }\end{array}$ & $\begin{array}{l}\text { Given the interest of the OSM research community in } \\
\text { lean, you will be interested in learning about its effect on } \\
\text { psychological trust. }\end{array}$ \\
\hline \multicolumn{3}{|l|}{ IMPROVEMENT } \\
\hline Add a Z-moderator & $\begin{array}{l}\mathrm{X} \\
\mathrm{Z}\end{array}$ & $\begin{array}{l}\text { Given this conversation's acceptance of } \mathrm{X} \rightarrow \mathrm{Y} \text {, you'll } \\
\text { be interested in my proposal that } \mathrm{Z} \text { operates as a } \\
\text { moderating condition. }\end{array}$ \\
\hline Add a Z-mediator & $\mathrm{X} \rightarrow \mathrm{Z} \rightarrow \mathrm{Y}$ & $\begin{array}{l}\text { Given this conversation's acceptance of } \mathrm{X} \rightarrow \mathrm{Y} \text {, you'll be } \\
\text { interested in my proposal that } \mathrm{Z} \text { operates as a mediating } \\
\text { factor. }\end{array}$ \\
\hline Add an $\mathrm{X}$ & 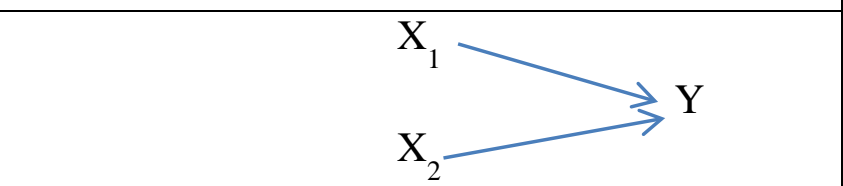 & $\begin{array}{l}\text { Given this conversation's acceptance of } \mathrm{X} \rightarrow \mathrm{Y} \text {, you'll } \\
\text { be interested in my proposal that the explanation of } \mathrm{Y} \text { is } \\
\text { significantly enhanced by the addition of } \mathrm{X}_{2} \text {. }\end{array}$ \\
\hline Add a Y & $\rightarrow \mathrm{Y}_{1}$ & $\begin{array}{l}\text { Given this conversation's acceptance of } \mathrm{X} \rightarrow \mathrm{Y}_{1} \text {, you'll } \\
\text { be interested in my proposal that } \mathrm{X} \text { also explains } \mathrm{Y}_{2} \text {. }\end{array}$ \\
\hline $\begin{array}{l}\text { Build out a proposition } \\
\text { into a complex model }\end{array}$ & $\begin{array}{l}\mathrm{X}_{2} \rightarrow \mathrm{X}_{1} \rightarrow \mathrm{Y}_{1} \\
\mathrm{X}_{1} \rightarrow \mathrm{Y}_{1} \rightarrow \mathrm{Y}_{2}\end{array}$ & $\begin{array}{l}\text { Given this conversation's acceptance of } \mathrm{X} \rightarrow \mathrm{Y} \text {, you'll be } \\
\text { interested in my proposal to "graft on" an antecedent } \\
\text { condition }\left(\mathrm{X}_{2}\right) \text { or subsequent outcome }\left(\mathrm{Y}_{2}\right) \text {. }\end{array}$ \\
\hline
\end{tabular}

From Whetton (2009) 
Table 4

Generic Research Paradoxes

\begin{tabular}{|c|c|}
\hline Paradox & Description \\
\hline Organization & $\begin{array}{l}\text { - What seems to be an organized (structured) phenomenon is in reality an unorganized (unstructured) phenomenon. } \\
\text { - What seems to be an unorganized (unstructured) phenomenon is in reality an organized (structured) phenomenon. }\end{array}$ \\
\hline Composition & $\begin{array}{l}\text { - What seem to be assorted heterogeneous phenomena are in reality composed of a single element. } \\
\text { - What seems to a single phenomenon is in reality composed of assorted heterogeneous elements. }\end{array}$ \\
\hline Abstraction & $\begin{array}{l}\text { - What seems to be an individual phenomenon is in reality a holistic phenomenon. } \\
\text { - What seems to be a holistic phenomenon is in reality an individual phenomenon. }\end{array}$ \\
\hline Generalization & $\begin{array}{l}\text { - What seems to be a local phenomenon is in reality a general phenomenon. } \\
\text { - What seems to be a general phenomenon is in reality a local phenomenon. }\end{array}$ \\
\hline Stabilization & $\begin{array}{l}\text { - What seems to be a stable and unchanging phenomenon is in reality an unstable and changing phenomenon. } \\
\text { - What seems to be an unstable and changing phenomenon is in reality a stable and unchanging phenomenon. }\end{array}$ \\
\hline Function & $\begin{array}{l}\text { - What seems to be a phenomenon that functions ineffectively as a means for the attainment of an end is in reality a } \\
\text { phenomenon that functions effectively. } \\
\text { - What seems to be a phenomenon that functions effectively as a means for the attainment of an end is in reality a phenomenon } \\
\text { that functions ineffectively. }\end{array}$ \\
\hline Evaluation & $\begin{array}{l}\text { - What seems to be a good phenomenon is in reality a bad phenomenon. } \\
\text { - What seems to be a bad phenomenon is in reality a good phenomenon. }\end{array}$ \\
\hline Correlation & $\begin{array}{l}\text { - What seem to be unrelated (independent) phenomena are in reality correlated (interdependent). } \\
\text { - What seem to be correlated (interdependent) phenomena are in reality unrelated (independent). }\end{array}$ \\
\hline Co-Existence & $\begin{array}{l}\text { - What seem to be phenomena that can exist together are in reality phenomena that cannot exist together. } \\
\text { - What seem to be phenomena that cannot exist together are in reality phenomena that can exist together. }\end{array}$ \\
\hline Co-Variation & $\begin{array}{l}\text { - What seems to be a positive co-variation between phenomena is in reality a negative co-variation between phenomena. } \\
\text { - What seems to be a negative co-variation between phenomena is in reality a positive co-variation between phenomena. }\end{array}$ \\
\hline Opposition & $\begin{array}{l}\text { - What seem to be similar (nearly identical) phenomena are in reality opposite phenomena. } \\
\text { - What seem to be opposite phenomena are in reality similar (nearly identical) phenomena. }\end{array}$ \\
\hline Causation & $\begin{array}{l}\text { - What seems to be the dependent phenomenon in a causal relation is in reality the independent phenomenon. } \\
\text { - What seems to be the independent phenomenon in a causal relation is in reality the dependent phenomenon. }\end{array}$ \\
\hline
\end{tabular}

From Davis (1971) 


\section{Table 5}

Guidelines for Development of Theoretical Constructs

To the extent possible, use generally accepted scholarly constructs, and stick with their proper names.

- Express as a noun or a 2-3 word noun phrase.

- Use your creativity in the way that you combine constructs, not in the names that you give them. Do not use multiple boxes to express or operationalize a single construct.

Try to maintain a consistent level of specificity among $\mathrm{X}$ and $\mathrm{Y}$ constructs.

Avoid mixing different kinds of constructs and levels of analysis.

- Distinguish between single-level and multi-level constructs

- Be cautious about using them together, within a single $\mathrm{X}->\mathrm{Y}$ proposition.

Given the expectation that strong theoretical propositions should be testable, avoid the use of exceptionally broad, very general constructs.

Be sure that every box qualifies as a variable and that it is capable of being acted upon.

- Variable: can take on values ranging from high to low

- Capable of being acted upon: a cause or an effect

- No broad topics, such as "environmental conditions," "gender theory" or "ecotourism"

- Don’t include steps in a process flow, such as "decide to purchase," "initiate a purchase" or "approve a purchase"

- No logical or developmental sequences, such as "early,” "middle” or "late” stages

In addition to the focal construct, also include complementary combinations with related antecedents and outcomes.

- Focal construct: the subject of your current scholarly interest

- Complementary construct: what combines with your focal construct to form a proposition

- Either the focal or complementary construct can function as an X-antecedent or a Y-outcome From Whetton (2009) 
Table 6

Threats to Validity

\begin{tabular}{|c|c|c|}
\hline Type & Definition & Selected Threats \\
\hline Internal Validity & $\begin{array}{l}\text { - Does their covariation result from a causal } \\
\text { relationship? } \\
\text { - Validity of inference about whether there is a } \\
\text { causal relationship }\end{array}$ & $\begin{array}{l}\text { - Selection } \\
\text { - Maturation } \\
\text { - Instrumentation } \\
\text { - Attrition } \\
\text { - Regression to the mean }\end{array}$ \\
\hline External Validity & $\begin{array}{l}\text { - Generalizations from samples of persons, settings } \\
\text { and times to constructs } \\
\text { - Validity of inferences about where the cause-effect } \\
\text { relationships hold over variation in persons, } \\
\text { settings, treatment variables and measurement } \\
\text { variables }\end{array}$ & $\begin{array}{l}\text { - Interaction of causal relationship with } \\
\text { selection of respondents } \\
\text { - Interaction of causal relationship with other } \\
\text { factors } \\
\text { - Interaction of causal relationship with } \\
\text { outcomes } \\
\text { - Interaction of causal relationship with settings } \\
\text { - Context-dependent mediation }\end{array}$ \\
\hline Construct Validity & $\begin{array}{l}\text { - Validity of inferences about higher order } \\
\text { constructs that represent sampling particulars } \\
\text { - Generalizations from operations to constructs }\end{array}$ & $\begin{array}{l}\text { - Inadequate understanding of constructs } \\
\text { - Construct confounding } \\
\text { - Mono-operation bias } \\
\text { - Mono-method bias } \\
\text { - Confounding constructs with levels of analysis } \\
\text { - Reactivity of self-reports } \\
\text { - Researcher expectancies }\end{array}$ \\
\hline $\begin{array}{c}\text { Statistical Conclusion } \\
\text { Validity }\end{array}$ & $\begin{array}{l}\text { - Appropriate use of statistics to infer whether the } \\
\text { presumed independent variables and dependent } \\
\text { variables covary } \\
\text { - Validity of inference about correlation between } \\
\text { treatment and outcome }\end{array}$ & $\begin{array}{l}\text { - Low statistical power } \\
\text { - Violation of assumptions } \\
\text { - Fishing } \\
\text { - Unreliability of measures } \\
\text { - Restriction of range } \\
\text { - Heterogeneity of respondents } \\
\text { - Inaccurate effect size estimation }\end{array}$ \\
\hline
\end{tabular}


Table 7

Approaches to Measurement Scales in Non-U.S. Cultures

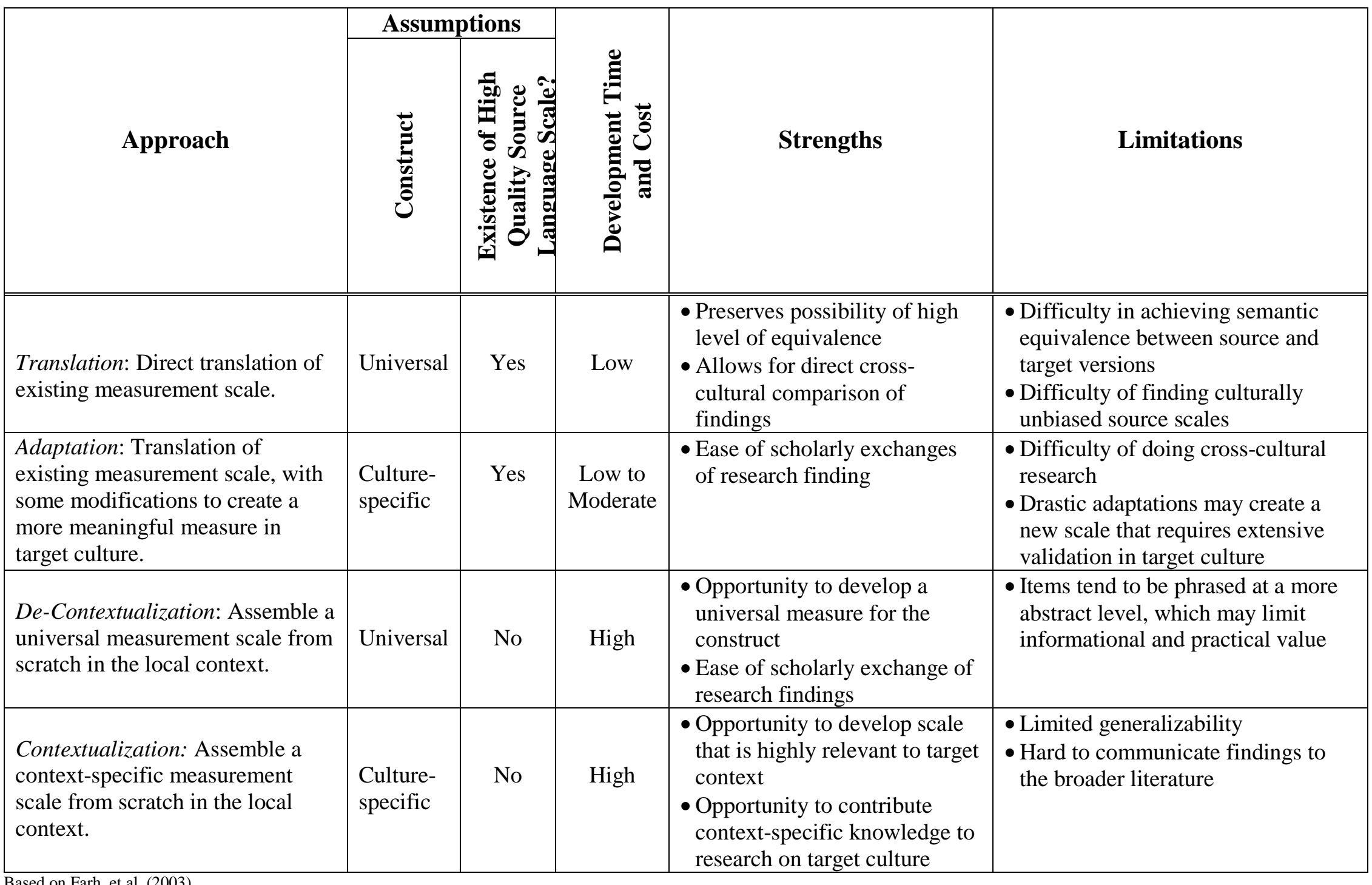

Based on Farh, et al. (2003) 
Table 8

Strengths and Weaknesses of Analytic Methods

\begin{tabular}{|c|c|c|c|c|}
\hline Method & Goals & Examples & Ideals & Critique \\
\hline $\begin{array}{l}\text { Theory } \\
\text { Validation }\end{array}$ & $\begin{array}{l}\text { - Inference: sample to population } \\
\text { - Prediction: past to future } \\
\text { - Description: patterns in data sets } \\
\text { - Hypothesis testing: increasing confidence } \\
\text { in a theoretical explanation } \\
\text { - Generalization: expanding the range of a } \\
\text { theoretical explanation }\end{array}$ & $\begin{array}{l}\text { - Regression } \\
\text { - Principal component and } \\
\text { factor analysis } \\
\text { - ANOVA, MANOVA } \\
\text { - Structural equation } \\
\text { modeling } \\
\text { - Game theory } \\
\text { - Time series analysis } \\
\text { - Optimal control theory } \\
\text { - Simulation } \\
\text { - Trend analysis } \\
\text { - Big data } \\
\end{array}$ & $\begin{array}{l}\text { - Objectivity } \\
\text { - Neutrality } \\
\text { - Replicable } \\
\text { procedures } \\
\text { - Discovery of causal } \\
\text { laws } \\
\text { - Abstraction } \\
\text { - Precision } \\
\text { - Rigor } \\
\text { - Verifiability }\end{array}$ & $\begin{array}{l}\text { - Oversimplification } \\
\text { - Unacknowledged } \\
\text { subjectivity of } \\
\text { definitions and } \\
\text { procedures }\end{array}$ \\
\hline $\begin{array}{l}\text { Theory } \\
\text { Development }\end{array}$ & $\begin{array}{l}\text { - Explication: how or why } \\
\text { - Detail: adding depth to theoretical } \\
\text { explanation } \\
\text { - Empathy: connecting abstract ideas to } \\
\text { human experience } \\
\text { - Exploration: seeking unacknowledged } \\
\text { antecedents, unanticipated consequences }\end{array}$ & $\begin{array}{l}\text { - Observation } \\
\text { - Historical research } \\
\text { - Content analysis } \\
\text { - Focus groups } \\
\text { - Unstructured and semi- } \\
\text { structured interviews } \\
\text { - Case studies } \\
\text { - Ethnographies } \\
\text { - Grounded studies } \\
\text { - Document analysis } \\
\text { - Thick data } \\
\text { - Big data }\end{array}$ & $\begin{array}{l}\text { - Rich description } \\
\text { - Meaning } \\
\text { - Qualified arguments } \\
\text { - Context-specific } \\
\text { description } \\
\text { - Reflection } \\
\text { - Connection }\end{array}$ & $\begin{array}{l}\text { - Subjectivity } \\
\text { - Sloppy observations } \\
\text { masquerading as } \\
\text { interpretation } \\
\text { - Intrusion of the } \\
\text { researchers in all } \\
\text { representations }\end{array}$ \\
\hline Mixed & $\begin{array}{l}\text { - Make quantitative results more } \\
\text { understandable } \\
\text { - Understand broader applicability of small } \\
\text { sample qualitative results } \\
\text { - Robust description and interpretation }\end{array}$ & $\begin{array}{l}\text { - Analyze documents and } \\
\text { behavior } \\
\text { - Simulation } \\
\text { - Survey research }\end{array}$ & $\begin{array}{l}\text { - } \text { Balance } \\
\text { - Compensating } \\
\text { strengths } \\
\text { - Cancelling } \\
\text { weaknesses } \\
\text { - Inclusive outcomes } \\
\end{array}$ & $\begin{array}{l}\text { - Shallow application of } \\
\text { intrinsically } \\
\text { incompatible methods }\end{array}$ \\
\hline
\end{tabular}

